\title{
Efficacy of non-halofuginone-based strategies to prevent or treat cryptosporidiosis in bovine calves: A systematic review
}

\author{
Dr. Julii Brainard ${ }^{1}$ \\ Dr. Charlotte C. Hammer ${ }^{2}$, charlottehammer@gmx.net \\ Dr. Kevin Tyler ${ }^{1}$ \\ Prof. Paul R. Hunter ${ }^{1}$ \\ ${ }^{1}$ Norwich Medical School, University of East Anglia, Norwich NR4 7TJ \\ ${ }^{2}$ European Programme for Intervention Epidemiology Training (EPIET) \\ Corresponding author = Julii Brainard, j.brainard@uea.ac.uk
}

Word count: 7500 without references

\# of tables: 1

Figure count: 178

Abstract word count: 230

\# of references: 88 references

\begin{abstract}
Cryptosporidiosis is a common illness in young cattle that causes high morbidity and some mortality. A common prophylactic treatment are halofuginone products but it seems likely disease could be reduced by other other pharmacological products or some management strategies. We undertook a systematic review and meta-analyses on key outcomes for treatment of calves before and after 5 days of age with any management strategy, any nutritional strategy or any non-halofuginone product.
\end{abstract}

A systematic literature search was undertaken with data extracted for outcomes = oocyst shedding, diarrhea, mortality and weight gain. Experiments had to describe results for same age animals in contemporary arms. Control animals had to be observed concurrently in planned experiments (pre-post and case-control studies were not eligible). Both randomized and other clinically controlled trials were eligible. Results were subgrouped by study design and outcomes were described in detail where at least two articles described the same treatment strategy.

55 articles were found. Significantly lower incidence of oocyst shedding, diarrhea burden and mortality was reported in many experimental arms, especially when animals started treatment before 5 days old. Weight gain was not mostly affected by treatment, however, by three weeks of age.

The evidence base is at least encouraging but insufficient about paromomycin, bumped kinase inhibitors and azithromycin treatment, especially for diarrhea and oocyst shedding, given late or early. Azithromycin is the most promising of these.

\section{Keywords}

Chemoprophlaxis; calves; cryptosporidiosis; diarrhea; dairy 


\section{Introduction}

\section{Background}

Cryptosporidium parvum is a common protozoa parasite in cattle. It causes chronic diarrhea leading to delayed growth, considerable morbidity and potentially death (Thomson et al. 2017; Wells and Thomson 2014). Young calves (under six weeks old) are at greatest risk of both catching and spreading pathogenic infection (Silverlås et al. 2009; Wells and Thomson 2014). Economic costs in Great Britain were estimated in 2014 to be $£ 100-£ 200$ per infected calf (Shaw 2014), arising mostly from veterinary treatment, need for higher nutritional inputs and lower weight gain. Prevalence of $C$. parvum in stool samples of European cattle herds were reported to range from 13-100\% (Imre and Dărăbus 2011). Cattle are recognized as an especially important reservoir for $C$. parvum, which can spread from cattle to other animals or to humans through many routes (Brankston et al. 2018; Hunter and Thompson 2005; Wells and Thomson 2014). Globally, infection from C. parvum and other Cryptosporidium subtypes (eg. C. hominis) are considered important contributors to combined total human deaths from diarrheal illness (Vermeulen et al. 2017). Large outbreaks in humans (affecting dozens or even hundreds of people) from pathogenic $C$. parvum infection regularly occur in Europe (Cacci and Chalmers 2016). Control of $C$. parvum is therefore highly desirable for good animal welfare, to reduce risks to human health and to limit economic losses in affected industries.

Prophylactic and treatment options for C. parvum infection are limited (Wells and Thomson 2014); for instance, in the UK only one product is licensed for the treatment of calves (halofuginone lactate marketed as Halocur ${ }^{\circledast}$ ). We undertook research elsewhere (Author-names-suppressed under review) to evaluate halofuginone treatment for cryptosporidiosis in young calves. This review focuses instead on summarizing scientific evidence about other treatments that may be effective, using systematic review and meta-analysis methods.

\section{Methods}

PRISMA literature search reporting guidelines were followed (Toews 2017).

\section{Population and other inclusion and exclusion criteria}

Population of interest was cows (Bos Taurus). Articles on humans, related species such as buffalo or yaks, and other animals were ineligible. Studies on hybrids of cattle with other animals (eg., beefalo) or mixed species herds (of Bos Taurus mixed with others) were considered individually, in case they provided sufficient cattle-specific information to be informative. Selected studies had to address outcomes related to C. parvum; evidence that other Cryptosporidium subspecies are likely to be pathogenic in cows is weak (Thomson et al. 2017; Wells and Thomson 2014).

\section{Intervention}

Eligible were any management strategy, drugs or disinfection treatment administered in an attempt to reduce incidence or severity of cryptosporidiosis in cows. Interventions could be either prophylactic, so very early in life (before 5 days old) or relatively late and therefore more likely to be treatment for existing or developing symptoms (age 5 days + ). The vast majority of calves suffering from cryptosporidiosis are under 1 month old (Wells and Thomson 2014). The threshold of five days was chosen to reflect a likely point of onset of symptoms and established infection, typically on day 4 or 5 of 
life if calves were exposed in the first 24 hours after birth, which they often are (Erbe 2010). Most of the selected studies described or presumed that natural infection had already occurred.

\section{Inclusion criteria}

Only deliberate experiments with concurrent untreated comparison animals were included. Pre-post and case-control designs were not eligible. There were no limits on location or publication date. Studies were excluded if not available in a language known to the authors (English, German, Spanish or French) or if the article could not be easily translated into English using Google Translate. Articles without abstracts were excluded.

\section{Outcomes of experiments}

Studies had to address at least one of these outcomes:

- Clinically detectable infection in (shedding from) live animals, of $C$. parvum.

- Fecal scoring consistency: usually on scales of 1-3, 0-3, 0-4 etc., to describe severity of diarrhea

- Measures of weight gain

- Mortality

- Any treatment or strategy not halofuginone-based

\section{Reference Sources}

The search was mostly within peer-review research. Literature databases were chosen following recommendations about the most comprehensive bibliographic sources for veterinary science research (Grindlay et al. 2012). Searched databases were: Scopus, CAB International abstracts, Pubmed and Embase. A limited grey literature search was undertaken of three government databases via websites: The UK Dept for Food and Rural Affairs, The US Dept. of Agriculture library (at Cornell University) and The European Commission, Agricultural and Rural Development section. Conference proceedings were not searched.

\section{Search Strategy}

From preliminary literature scoping, we selected two exemplar articles that met our inclusion criteria (De Waele et al. 2010; Fayer and Ellis 1993). The search terms were developed and validated by making sure searching using the below terms found both exemplar articles with a minimum of extraneous (irrelevant search return results). Within the peer-review bibliographic databases, we searched for, among title/abstract/keywords:

At least one of (Cryptosporidum , C. parvum, cryptosporidiosis)

AND

At least one of (calf, cattle, cow, bull, dam, dairy, beef, herd, calves)

Grey literature search terms were cryptosporidium, cryptosprodiosis, and parvum. Some especially thorough and recent review papers about cryptosporiodiosis (Beaver et al. 2019; Johnson et al. 2011; Olias et al. 2018; Taylor and Bartram 2012) were checked for eligible articles missed by our search strategy. Forward and backward citation searches of included articles were not done to look for additional studies. 


\section{Study selection}

After de-duplication, titles and abstracts were independently screened by two investigators (JB and $\mathrm{CCH}$ ). Items were chosen for full text review or excluded. Selection disagreements were resolved by discussion or by referring to another co-author (PRH). Full texts were obtained where possible.

Decisions about final inclusion or exclusion were made after full text review.

\section{Quality Assessment}

Modified questions from Cochrane risk of bias assessment criteria (Higgins and Wells 2011) were used to generate a customized quality assessment decision form (Supplementary file 1). Full text review, data extraction and quality assessment were mostly undertaken by a single author (JB), with assessments on German language articles done by $\mathrm{CCH}$. Trial quality was indicated by colour coding (green = low risk of bias, yellow $=$ unclear, red $=$ high risk of bias) available in the meta-analysis software (REVMAN). Where more than one experiment was described within a single article a separate risk of bias was calculated for individual experiments (different answers to the quality checklist questions); this proved to be rarely required. Risk of bias was not addressed in detail with regard to individual results, but is presented for completeness of reporting.

\section{Reporting and Synthesis}

Meta-analysis was applied with random-effects due to expected high heterogeneity, using REVMAN version 5.3 (Deeks et al. 2011). Meta-analysis results are described narratively with reference to forest plots. The forest plots distinguish RCT vs. CCT results. Significance level was set at $p \leq 0.05$. We planned to generate funnel plots to look for publication bias if at least six studies contributed outcome data for a specific treatment.

How to best pool extracted data depending on the specific outcome. Mortality was simple: of the animals that started the trials in each arm, how many died during the monitoring period could be input to calculate pooled risk ratios. However, data for amount (or severity) of oocyst shedding or diarrhea incidence were reported using a variety of scales. Oocyst shedding was reported (for instance) as prevalence of animals with any detected oocysts, prevalence of animals shedding above a certain threshold or by average score for the arm on specific dates (scoring from 0 to higher levels, where higher level numbers meant more oocysts detected). Fecal consistency was typically reported on multilevel scales (from 0 to 2, 3 or 4, where higher levels were more liquid). Weight might be reported as average daily weight gain, total weight at trial end, or weight change since birth. These diverse metrics were measuring the same outcomes but on different scales. They were therefore compared in metaanalysis using standard mean differences (SMDs). SMDs standardize for differences between arms rather than rely on the same instrument being used to measure an outcome in all trials. Lower SMD was a better outcome for calves with regard to diarrhea or oocyst shedding but higher SMD value (above 0 ) was the preferred outcome with respect to weight gain. However, rarely was variance reported with these primary outcomes (oocyst shedding on individual sampling days, much less for the entire monitoring period. Therefore, standard deviations were calculated from the daily averages. Eg., if the only fecal scores supplied for a group of animals for just 3 dates during the monitoring period were daily averages $=(1,2,3)$ the mean for the monitoring period was assigned to equal $2, \mathrm{sd} 1$. Comparing scores transformed thus was valid because the original metrics fundamentally measured the same outcome (eg. weight gain, intensity of oocyst shedding or diarrhea) and were compared between studies using SMDs. 


\section{Stratification and subgrouping}

Exposure soon after birth for most animals means that most untreated calves are symptomatic by 5 days old (Erbe 2010). The pathology of disease is worse in young animals; older infected animals are more resilient and have less morbidity and mortality. Results were therefore divided by whether treatment was relatively early (relatively prophylactic, started before calves were 5 days old), or relatively late: started when animals were age 5 days or older.

Where at least 2 different studies had eligible outcomes for specific treatments (early or late), the results are described in detail, and pooled in meta-anlaysis if possible. The eligible trials (at least 2 experiments for each treatment) addressed: bumped kinase inhibitors, colostral whey, decoquinate, individual vs. group housing, lasalocid-Na, oral oocyst vaccine, niazoxanide/metrodinazole, oligosaccharides, paromomycin and sulphadimine.

Many other experiments tested other specific nutritional strategies or supplements, but none of these experiments were repeated and therefore their results are inconclusive and evidence very limited. These results (for drugs, supplements or feeding practices not tested in multiple studies) are described in a single narrative summary table without additional commentary.

\section{Interpretation}

To facilitate interpretation of the review results we employ terms as defined below in our narrative. These definitions are not based on any existing taxonomy and are not proposed to be the best way to interpret all such data, but defining them very specifically may help the reader to assess the certainty of evidence and thus make the narrative meaningful.

"Early" treatment means animals started treatment before age 5 days (on average in a group)

"Encouraging" Reported as beneficial in a single trial without strongly contradictory evidence, or two very small trials.

"Insufficient/Limited": Just two studies provided data.

"Late" treatment means animals started treatment at age 5 days or older (on average in that trial arm)

"Probably": $\geq 3$ studies provided data and they agree about effect direction even if pooled effect wasn't significant at $p<0.05$.

"Promising" treatment showed consistent benefits in at least 2 outcomes although data also limited

"Risk Ratio" seen on meta-analysis plots for mortality. Values $<1$ favour experiment (fewer deaths in experimental treatment arm) and values $>1$ favour controls (fewer deaths in control arm).

"Significant", means 95\% confidence interval for Risk Ratio was over or under 1.0, or standard mean difference was entirely above or below 0 .

"Standard mean difference" (SMD). Because different studies measured and reported the same things in different ways, such as intensity of oocyst shedding, the diverse metrics are compared in meta- 
analysis using standard mean differences. SMD standardizes for differences between arms rather than assume a common scale metric in all trials. Used for measures of weight gain, diarrhea burden and oocyst shedding intensity. See key at bottom of forest plot; lower SMD is better outcome for calves for diarrhea or oocyst but higher SMD value (above 0 ) is better for weight gain measures.

"Very Limited": Only one study provided relevant data on a specific outcome

\section{RESULTS}

There were 2475 mostly unique articles found in scientific databases. There were no hits on the USDA library site and 14 hits on the EC site (none of which were eligible for inclusion). On the UK DEFRA site there were 33 hits, most of which related to prevalence in humans or human disease risk factors; none related to disease prevention in cattle.

66 articles were selected for full text review. Of these reports, four were unavailable. Eight articles were excluded after full text review leaving 55 eligible articles for this review. Most articles described randomized controlled trials (RCTs), but there were also non-randomised experiments (clinical controlled trials, CCTs). Often, several experiments were documented within a single report. Most reports addressed early treatment (starting by 4 days old).

All animals were Bos Taurus (no mixed species or hybrids), mostly Holstein breed or Holstein crosses, almost exclusively from dairy herds. There was a mix of sexes.

Supplementary Table 2 details risk of bias assessments for all included articles. 12 articles had four domains with low risk of bias, and three trials had low risk of bias in 5 domains. Most trials $(n=39)$ had moderate to high risk of bias. Treatments tried in at least two different scientific reports are listed below. Table 1 lists treatments that were described in only one published article.

\section{Azithromycin}

This drug was tested in three small-moderate size RCTs (5-15 animals in any one arm) and one small CCT (Elitok et al. 2005; 10 animals in each arm).

Weight was only an outcome in one trial, a late treatment CCT (Elitok et al. 2005) that tested doses of $0.5,1,1.5$ or $2 \mathrm{~g} /$ day on each animal. Surviving animals had higher total weight at 30 days old the higher the dose they had. Even the lowest dose animals $(0.5 \mathrm{~g} /$ day) had higher weight gain compared to controls (SMD 3.68, 1.55 to 5.82 ).

Fecal consistency was only reported on narratively for the azithromycin trials. Elitok et al. said that differences in the percentage of diarrheic calves between medicated and control groups were statistically significant $(P<0.05)$ and that diarrhoea disappeared from higher dose groups $(1.5$ or 2 $\mathrm{g} /$ day) by day 7 (no more specific data reported; no comparable data supplied for the control arm). Nasir et al. (2013) and Yagci et al. (2017) did not comment on group diarrhoea differences. Shobhamani et al. (2007) said that untreated calves were all diarrhoeic on day 7, 5 controls were still diarrheic on day 14 , and 3 controls were still diarrheic on day 21 . In contrast, among azithromycin-treated calves, only 4 had diarrhoea on day 7 and none had diarrhoea on day 9 or later. 
Oocyst excretion was reported in all of the tests of azithromycin. The results were better for the experimental treatment in all trials (see Figure 1a below).

Figure 1a. Oocyst excretion after treatment with Azithromycin

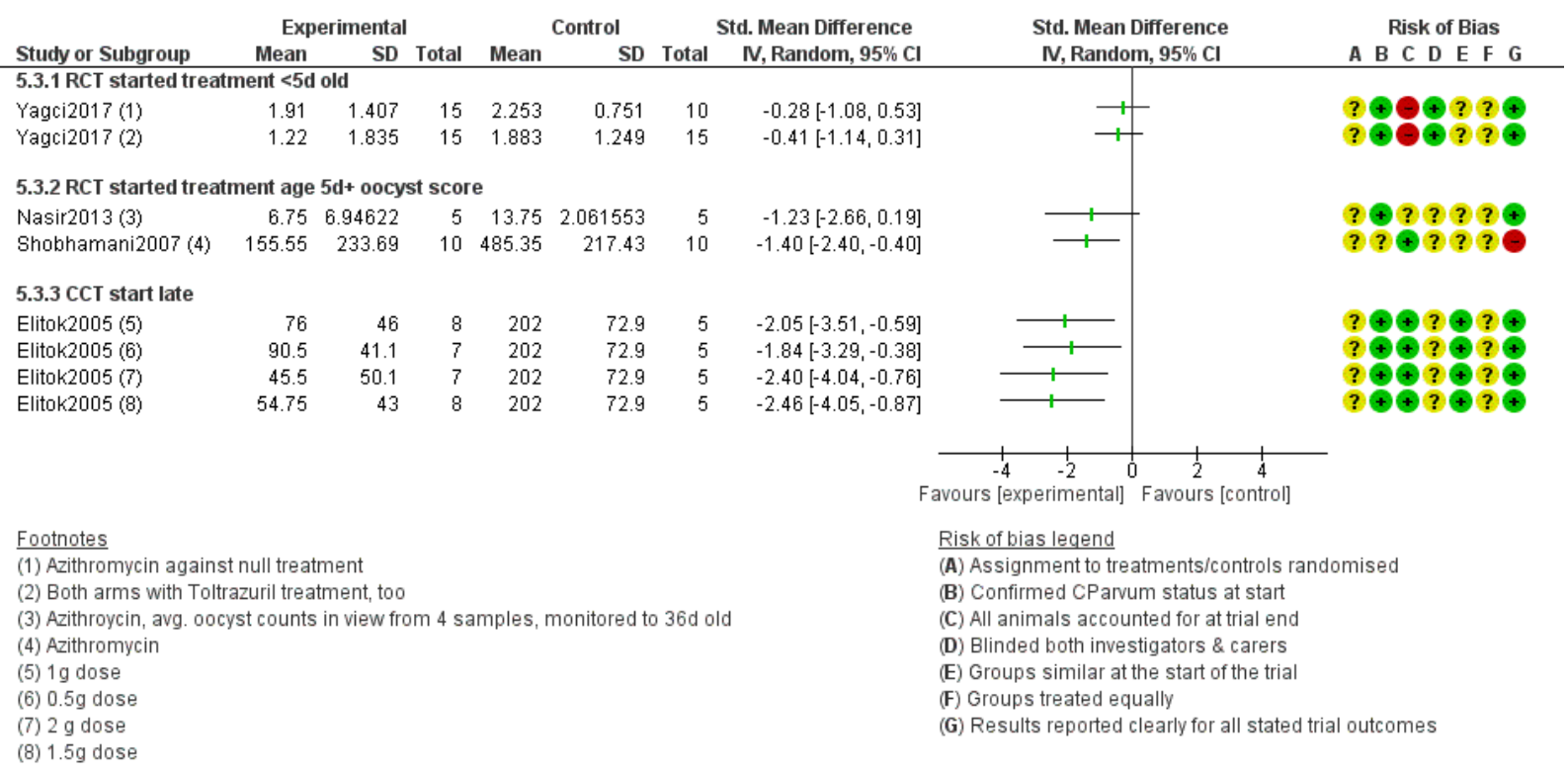

Mortality was commented upon in one CCT (late, Elitok et al., with 4 treatment doses/comparisons) and one early treatment RCT which can be divided into two comparisons depending on co-treatment drug (Yagci et al. 2017). Mortality was similar between all treatment arms in the late CCT (Elitok et al.; 2 or $3 / 10$ animals died in each treatment arm) but much higher in the untreated arm (5/10 died). A much higher fatality rate for controls was also seen in the early treatment RCT, Yagci2017: 8/10 untreated animals died compared to $2 / 15$ treated animals, and there were $3 / 15$ control deaths versus $0 / 15$ intervention deaths for animals treated simultaneously with another antimicrobial, toltrazuril. See figure below. The other trials on azithromycin (Nasir et al. 2013; Shobhamani et al. 2007) did not comment on mortality. 
Figure 1b. Mortality after treatment with Azithromycin

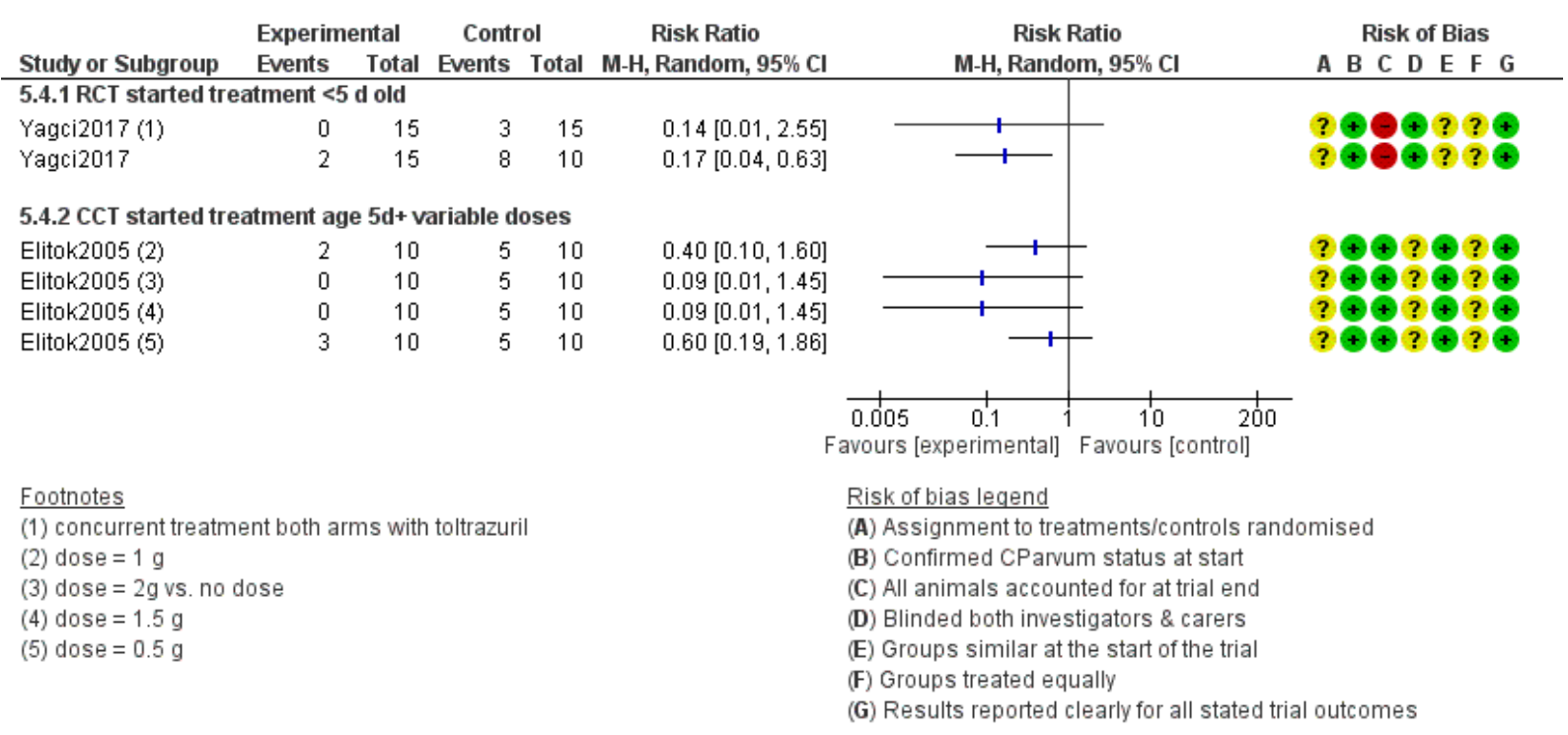

Azithromycin was effective at reducing oocyst shedding when given early or late. Mortality data on azithromycin treatment is limited but encouraging. Azithromycin treatment could be linked to benefits in three areas (mortality, oocyst shedding and weight gain) which makes it a promising treatment. Evidence about the effects of azithromycin treatment on diarrhea or weight gain is limited or very limited but also suggests benefits.

\section{Bumped Kinase Inhibitors}

Two experiments considered BKI inhibitors, especially BKI 1294. Neither addressed weight changes in treatment arms.

Fecal consistency was reported only in Schaefer et al. (2016, early RCT). Diarrhoeal intensity was lower in treatment arms (see Figure below), although not always significantly so. 
Figure 2a. Intensity of diarrhea scores after treatment with bumped kinase inhibitors

\begin{tabular}{|c|c|c|c|c|c|c|c|c|c|}
\hline \multirow[b]{2}{*}{ Study or Subgroup } & \multicolumn{2}{|c|}{ Experimental } & & \multicolumn{2}{|r|}{ Control } & \multicolumn{2}{|r|}{ Std. Mean Difference } & \multirow{2}{*}{$\begin{array}{l}\text { Std. Mean Difference } \\
\text { IV, Random, } 95 \% \mathrm{CI}\end{array}$} & Risk of Bias \\
\hline & Mean & SD & Total & Mean & SD & Total & IV, Random, 95\% Cl & & A B C D E F G \\
\hline \multicolumn{10}{|c|}{ 6.2.1 early RCT, BKI 1294 every 2 days } \\
\hline Schaefer2016 & 2.1875 & 1.016208 & 6 & 2.925 & 0.97358 & 6 & $-0.68[-1.86,0.50]$ & - & 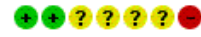 \\
\hline \multicolumn{10}{|c|}{ 6.2.2 early RCT, BKI 1294 twice daily } \\
\hline Schaefer2016 & 2 & 1.116116 & 6 & 3.175 & 0.843462 & 18 & $-1.24[-2.24,-0.24]$ & - & ๑๑????ย \\
\hline \multicolumn{10}{|c|}{ 6.2.3 early RCT, BKI 1517 twice daily } \\
\hline Schaefer2016 & 2.15 & 0.83324 & 6 & 3.175 & 0.843462 & 18 & $-1.18[-2.17,-0.18]$ & & $\odot \odot ? ? ? ? \odot$ \\
\hline \multicolumn{10}{|c|}{ 6.2.4 early RCT, BKI 1553 twice daily } \\
\hline Schaefer2016 & 2.55 & 0.975412 & 6 & 3.175 & 0.843462 & 18 & $-0.69[-1.64,0.26]$ & - & 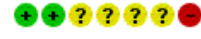 \\
\hline
\end{tabular}

Risk of bias legend

(A) Assignment to treatments/controls randomised

(B) Confirmed CParvum status at start

(C) All animals accounted for at trial end

(D) Blinded both investigators \& carers

(E) Groups similar at the start of the trial

(F) Groups treated equally

(G) Results reported clearly for all stated trial outcomes

Both Schaefer et al. (2016) and Lendner et al. (2015, an early CCT) looked at oocyst shedding after BKI 1294 supplementation. The Lendner et al. scores for oocyst shedding (treatment using BKI 1294 only) were presented as means ( 38.13 for intervention, 155.75 for controls) and $p$-value statistics using ANOVA and Mann-Whitney test ( $p=0.003)$, so not suitable for pooling. Diarrhoea was much worse for the untreated group.

The oocyst intensity data outcomes in Schaefer et al. (2016) were reported more clearly; see figure below. Less shedding was linked to all BKI treatments when given twice a day ( $5 \mathrm{mg} / \mathrm{kg}$ dose). BKI 1553 and BKI 1517 did not reduce oocysts as much as BKI 1294 had, yet the groups who received BKI 1553 and BKI 1517 had better clinical health scores than calves who received BKI 1294. Similarly, at a lower and more infrequent dose, in spite of reduction oocyst shedding, Schaefer et al. concluded that health condition of the BKI-1294 treated calves treated only once every 2 days $(10 \mathrm{mg} / \mathrm{kg})$ was no better than controls. "Bumped kinase inhibitor 1294 (BKI-1294) treatment every other day at $10 \mathrm{mg} / \mathrm{kg}$ produces a marginal clinical response in Cryptosporidium parvum-infected calves despite a significant reduction in parasite propagation." (p. 1858). 
Figure 2b. Oocyst shedding after treatment with bumped kinase inhibitors

\begin{tabular}{|c|c|c|c|c|c|c|c|c|c|}
\hline \multirow[b]{2}{*}{ Study or Subgroup } & \multicolumn{2}{|c|}{ Experimental } & \multirow[b]{2}{*}{ Total } & \multicolumn{2}{|r|}{ Control } & \multicolumn{2}{|r|}{ Std. Mean Difference } & \multirow{2}{*}{$\begin{array}{c}\text { Std. Mean Difference } \\
\text { IN, Random, } 95 \% \mathrm{Cl}\end{array}$} & Risk of Bias \\
\hline & Mean & SD & & Mean & SD & Total & IV, Random, $95 \% \mathrm{Cl}$ & & A B C D E F G \\
\hline \multicolumn{10}{|c|}{ 6.3.1 early CCT, BKI 1294} \\
\hline Lendner 2015 & 38.13 & 0 & 6 & 155.75 & 0 & 6 & Not estimable & & $\ominus \odot \odot ? ? ? \odot$ \\
\hline \multicolumn{10}{|c|}{ 6.3.2 early RCT, BKI 1294 every 2 days } \\
\hline Schaefer2016 & 6.93125 & 1.054561 & 6 & 7.99375 & 1.249125 & 6 & $-0.85[-2.05,0.36]$ & 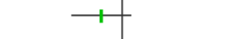 & ๑๑????? \\
\hline \multicolumn{10}{|c|}{ 6.3.3 early RCT, BKI 1294 twice daily } \\
\hline Schaefer2016 & 7.7125 & 0.458063 & 6 & 10.65 & 0.9426 & 18 & $-3.31[-4.69,-1.93]$ & $\longrightarrow$ & †૯???? \\
\hline \multicolumn{10}{|c|}{ 6.3.4 early RCT, BKI 1517 twice daily } \\
\hline Schaefer2016 & 8.1375 & 1.0636 & 6 & 10.65 & 0.9426 & 18 & $-2.50[-3.70,-1.29]$ & $\longrightarrow$ & ๑๑????? \\
\hline \multicolumn{10}{|c|}{ 6.3.5 early RCt, BKI 1553 twice daily } \\
\hline Schaefer2016 & 9.8 & 2.1408 & 6 & 10.65 & 0.9426 & 18 & $-0.62[-1.57,0.32]$ & 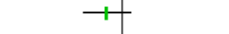 & †૯? ? ? ? \\
\hline
\end{tabular}

Risk of bias legend

(A) Assignment to treatments/controls randomised

(B) Confirmed CParvum status at start

(C) All animals accounted for at trial end

(D) Blinded both investigators \& carers

(E) Groups similar at the start of the tria

(F) Groups treated equally

(G) Results reported clearly for all stated trial outcomes

Only Lendner 2015 provided data on mortality. They reported one death in the intervention arm, no deaths in a sham treatment arm and 1 death in a control arm (infected but had no treatment, sham or active). These differences were not statistically significant.

The evidence in favour of treatment with any type of BKI is promising but limited or very limited.

\section{Colostral whey products}

Two trials described assessing oocyst shedding after colostral whey products were given to calves: Robert et al. (1991, early RCT) and Slacek et al. (1996, late RCT). Neither trial reported data that could be compared between arms on weight change, severity of diarrhea or mortality. It is not clear if the composition of colostral whey was adequately similar in the two trials. Robert et al. gave calves a colostrum whey product that had been subjected to curdling and processing with rennet. Slacek et al. described colostral whey-derived gammaglobulins given to calves age 10 or 17 days old as the treatment.

Both of the trials reported lower shedding in the experimental arm (figure below) but neither significantly so. It is not clear if the treatments are similar enough to combine their effects, but if they be considered adequately similar to put into a single meta-analysis, then the treatment still did not confer significant benefits in meta-analysis (SMD $-0.53,95 \% \mathrm{Cl}-1.34$ to 0.27 ). The treatment may still be considered somewhat encouraging in that the evidence was consistent, if also rather limited; very limited if separated by timing of treatment onset (plus only two trials and only a total of 34 animals).

Figure 3. Oocyst score indices after administration of colostral whey products 


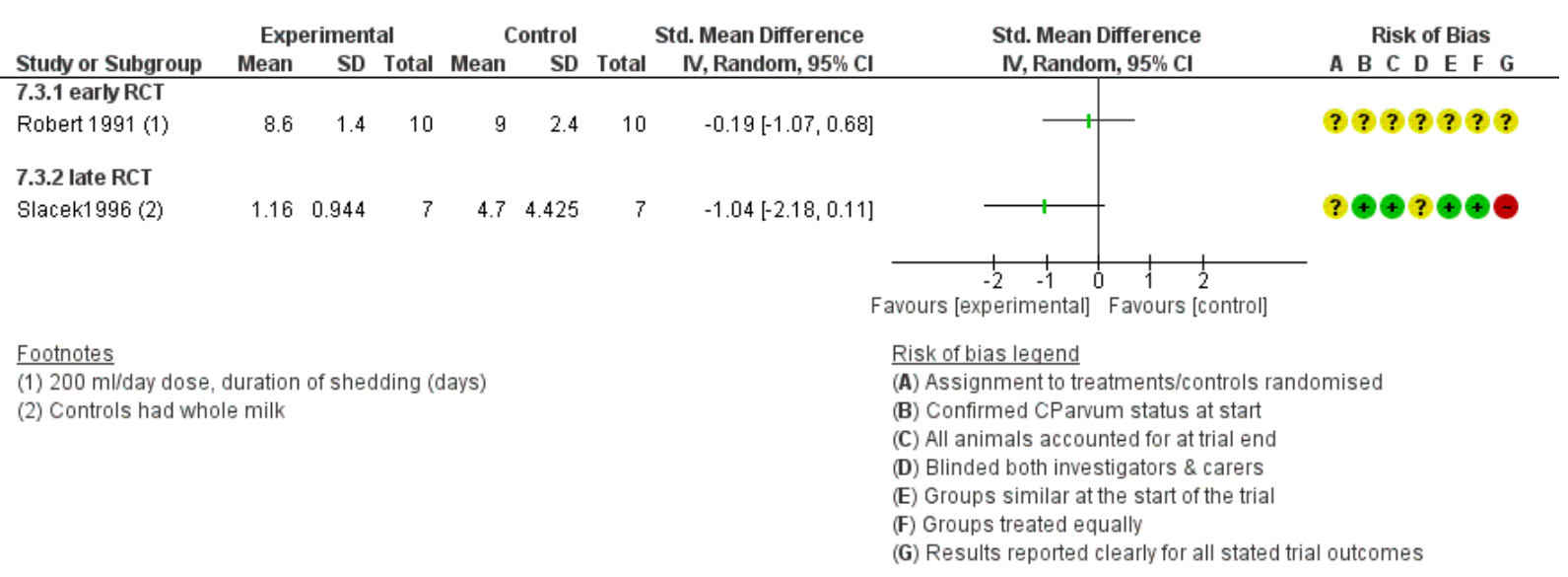

\section{Decoquinate}

Data are insufficient but encouraging for reducing mortality. It was tested in two small-moderate-size RCTs. Early (prophylactically) in Moore et al. (2003), and late in Lallemond et al. (2006). Oocyst shedding was not significantly lower in the control arm for the animals treated early (SMD 0.06, -0.41 to 0.52 ). Oocyst shedding was reduced in intervention animals (not significantly, SMD $-0.23,-0.74$ to 0.27 ) when decoquinate was administered late. Decoqinuate does not appear to reduce oocyst shedding. Mortality was reduced in experimental arms in both the early \& late studies, albeit insignificantly. Respective early and late mortality RRs were 0.76 (0.31-1.82) and 0.33 (0.01-7.87). Data were not available for impacts of decoquinate on weight gain or incidence of diarrhea.

Figures below show first oocyst shedding comparisons (SMDS) and second mortality (Risk Ratios) for decoquinate; neither comparison suggests consistent and significant differences between treatment and control groups. The treatment could be considered to be weakly promising.

\section{Figure 4a. SMD with regard to oocyst shedding after decoquinate treatment}

\begin{tabular}{|c|c|c|c|c|c|c|c|c|c|}
\hline \multirow[b]{2}{*}{ Study or Subgroup } & \multicolumn{3}{|c|}{ Experimental } & \multicolumn{2}{|c|}{ Control } & \multicolumn{2}{|r|}{ Std. Mean Difference } & \multirow{2}{*}{$\begin{array}{l}\text { Std. Mean Difference } \\
\text { IV, Random, } 95 \% \mathrm{Cl}\end{array}$} & Risk of Bias \\
\hline & Mean & SD & Total & Mean & SD & Total & IV, Random, $95 \% \mathrm{Cl}$ & & A B C D E F G \\
\hline \multicolumn{10}{|c|}{ 8.3.1 RCT started treatment $<5 \mathrm{~d}$ old } \\
\hline Moore2003 & 7.5 & 2.2 & 34 & 7.4 & 1.2 & 37 & $0.06[-0.41,0.52]$ & & $\odot \odot \odot \ominus ? \odot \ominus$ \\
\hline \multicolumn{10}{|c|}{ 8.3.2 RCT started treatment age $5 d+$} \\
\hline \multirow[t]{2}{*}{ Lallemand2006 (1) } & 31 & 24.1983 & 30 & 37 & 26.391 & 30 & $-0.23[-0.74,0.27]$ & - & 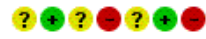 \\
\hline & & & & & & & & $\begin{array}{cccc}-1 & -0.5 & 0 & 0.5 \\
\text { Favours [experimental] } & \text { Favours [c }\end{array}$ & \\
\hline \multicolumn{8}{|c|}{$\frac{\text { Footnotes }}{\text { (1) Average \%prevalence in monitoring period, std-dev of that }}$} & \multicolumn{2}{|c|}{$\begin{array}{l}\text { Risk of bias legend } \\
\text { (A) Assignment to treatments/controls randomised } \\
\text { (B) Confirmed CParvum status at start } \\
\text { (C) All animals accounted for at trial end } \\
\text { (D) Blinded both investigators \& carers } \\
\text { (E) Groups similar at the start of the trial } \\
\text { (F) Groups treated equally } \\
\text { (G) Results reported clearly for all stated trial outcomes }\end{array}$} \\
\hline
\end{tabular}


Figure 4b. Mortality for animals treated with deconquinate

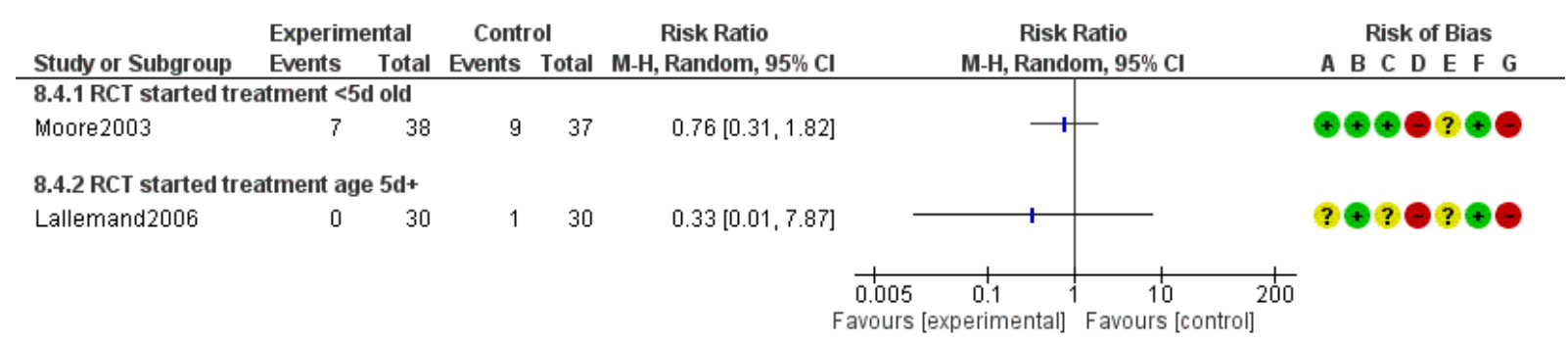

Risk of bias legend

(A) Assignment to treatments/controls randomised

(B) Confirmed CParvum status at start

(C) All animals accounted for at trial end

(D) Blinded both investigators \& carers

(E) Groups similar at the start of the trial

(F) Groups treated equally

(G) Results reported clearly for all stated trial outcomes

\section{Individual hutches rather than shared pens}

Two RCTs (both early implementation, De Waele et al. 2010 and Quigley et al. 1995) tested how calves were housed might affect symptoms of cryptosporidiosis: in individual (hutches) or shared pens. They both reported on diarrhea, oocyst shedding and mortality (but not weight gain). The hutches in Quigley et al. were brand new: had not housed animals before. The pens used in De Waele et al. were disinfected before the experiment started but were not described as never previously used. Fecal scores were only slightly (insignificantly) better in the individually housed animals than among the calves in shared pens, SMD $=-0.10$ (-0.45 to 0.25$)$. The variance for fecal scores in Quigley et al. was suboptimal because it was indicated by a single standard error value across both all arms.

Figure 5a. Diarrhoea scores when calves kept in individual not shared pens

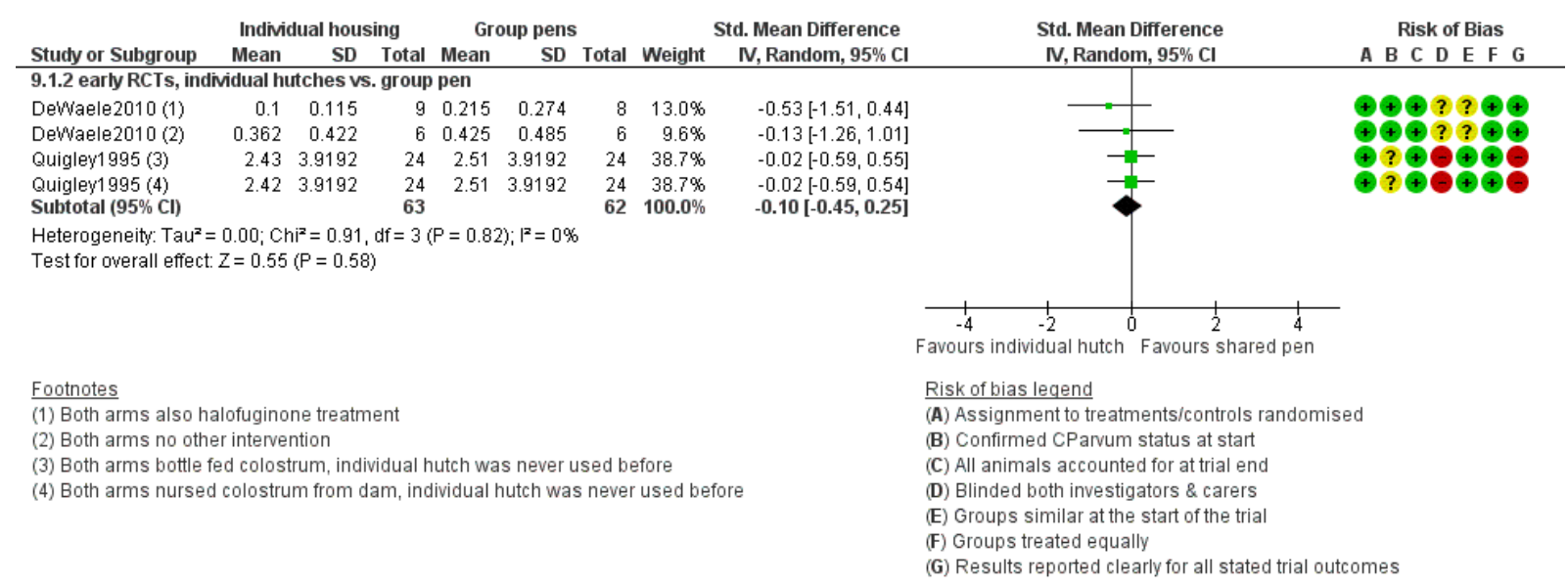

Oocyst shedding was lower in individual pens, significantly $(p=0.03)$ pooled SMD $-0.53(-1.01$ to -0.05$)$, with moderate heterogeneity $\left(I^{2}=36 \%\right)$. The pens in Quigley et al. 1995 had never been used before, unlike the pens in De Waele et al. (2010), so the housing conditions are not very identical. The variance 
for \% of animals shedding oocysts in Quigley et al. was also suboptimal or precise, because it indicated by a single standard error value across both all arms.

Figure 5b. Oocyst shedding after calves kept in individual not shared pens

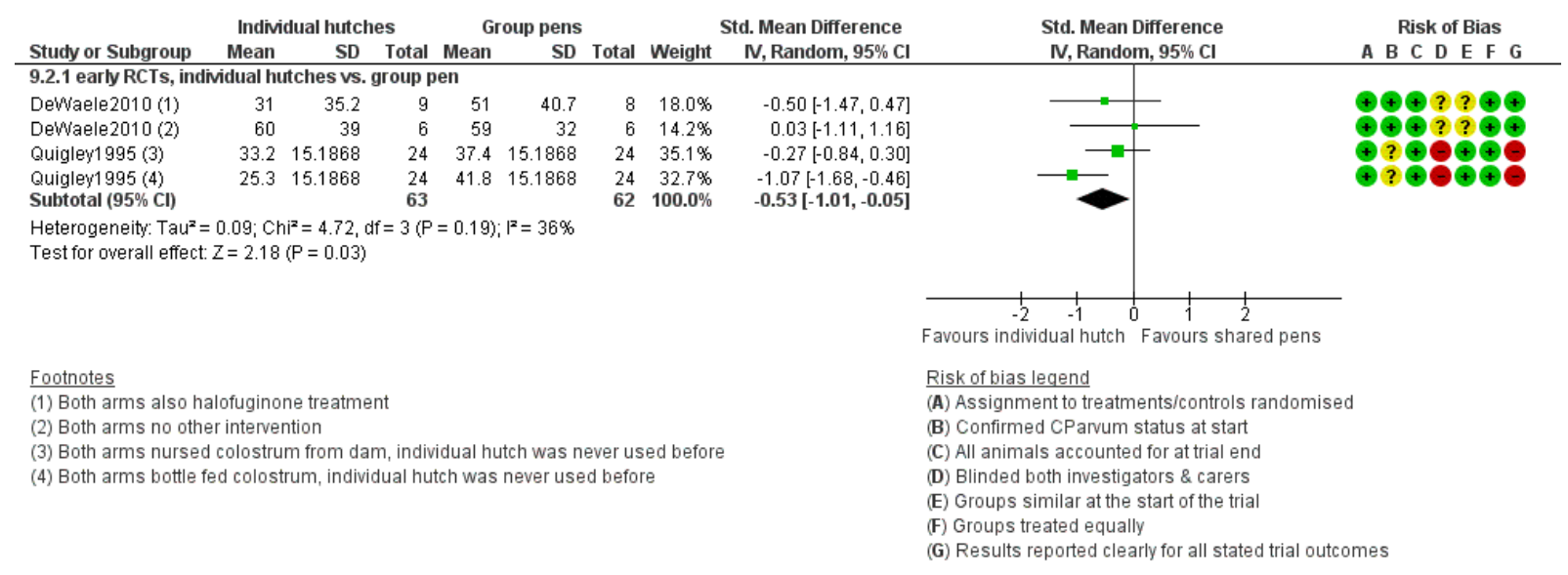

The evidence on mortality also had low heterogeneity (figure below, $I^{2}=0$ ). There was an insignificant (and inconsistent) reduction in mortality among calves kept in individual rather than shared pens (RR $0.87,0.26$ to 2.90 ). The evidence base is limited and the pooled RRs are based on just 111 animals. 
Figure 5c. Mortality after calves kept in individual not shared pens

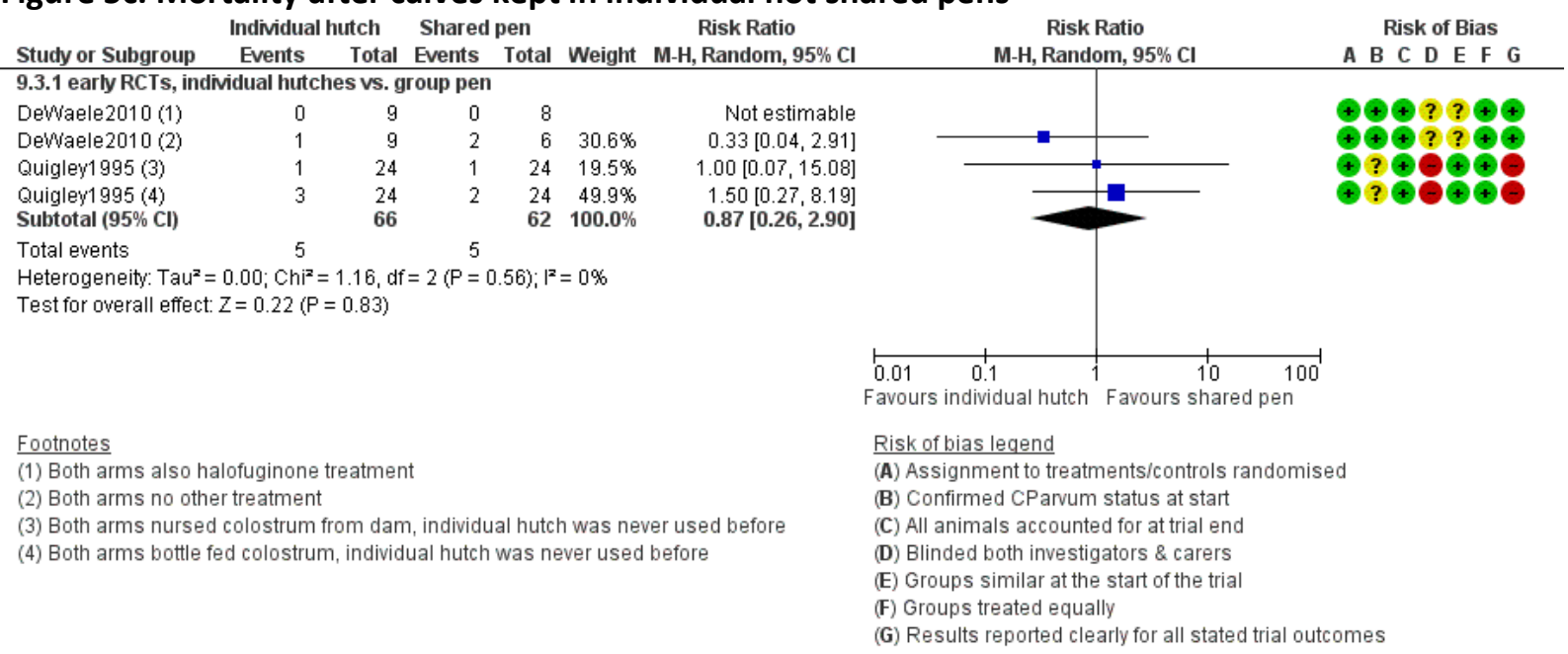

It may be useful to mention that Graef et al. (2018) found that confined crating of calves (compared to much larger individual box stalls) significantly increased oocyst shedding $p=0.05$. Quigley et al. (1995) described their individual pens as measuring $1.2 \times 2.4$ metres and bedded with sawdust and straw. De Waele et al. undertook their research in Ireland in 2005 (prior to January 2007 when veal crates were banned in the EU). They did not state dimensions but described the individual pens as " made of aluminum with a slatted wooden base" with straw bedding, where the animals stayed until 28 days old. Graef et al. (2018) described the confined crates as too small for animals $>10$ days old and that within them "calves may rise or lay down in sternal or lateral recumbancy, but they cannot turn around or ambulate". Manufacturer's pictures of the confined stalls products never show any form of bedding; bedding is not suited to the design. In contrast, box stalls in Graef et al. had "approximately $12.2 \mathrm{~m}^{2}$ (40 $\mathrm{ft}^{2}$ ) of space, bedded in sterile wood shavings, and had a mirror placed at eye-level for environmental enrichment". The Quigley et al. stalls are evidently smaller than those used in De Waele et al. but may be comparable to the pens used in Graef et al. These variations complicate comparison of differences.

Although oocyst shedding was lower among animals housed in individual pens, no reduction in mortality or diarrhea was linked to whether calves were housed individually or in shared pens. The evidence base is limited and inadequately specific about what aspect of the interventions caused effects (virgin pens or individual pens, size of pens, type of flooring, etc). On balance, confinement in individual pens was encouraging with regard to reducing oocyst shedding, but this was not clearly shown to lead to better health outcomes for animals. The studies on this treatment strategy have the merit of having relatively low risk of bias ( 5 low risk ratings in the 7 risk of bias domains), which strengthens the certainty of these findings.

\section{Lasalocid-Na}

Two studies considered this anti-microbial: Moon et al 1982 (late CCT, 12 animals total) and Murakoshi et al 2014 (early CCT, 12 animals total). Both studies did not report on weight gain or fecal consistency. Deaths were reported in Moon et al. but not clear how many from which groups; there was no mention of mortality in Murakoshi et al. (2014). 
Therefore, the only specific data on Lasalocid-Na treatment was for oocyst shedding. This was not reported in a format suitable for pooling. Moon et al. stated that oocyst shedding intensity was lower in treated animals (score $=2$ ) than in untreated calves (score $=7$, no variance supplied). Murakoshi et al. said that oocyst shedding was significantly lower in treated animals $(p<0.01)$ but did not provide raw data to evidence the claim (this publication was only a short conference abstract). The evidence about Lasalocid-Na was insufficient to draw conclusions.

\section{Evidence on either Niazoxanide or Metronidazole}

Niazoxanide was tested in two small experiments, both RCTs (Olivett et al. 2009; $n=20$, late) and (Schynder et al. 2009; $n=9$, both early and late). Animals in Olivett et al. were only enrolled if symptomatic and at least 4 days old. Most of the data reported from these trials were not suitable for pooling. Evidence was limited or very limited for any specific outcome.

Ollivett et al. (2009) found that weight gain was higher in the control group at $0.72 \mathrm{~kg} / \mathrm{d}$ vs. $0.68 \mathrm{~kg} / \mathrm{d}$, although this difference was not significant. Schnyder et al. (2009) collected weight information but did not report it.

Olivett et al. reported that diarrhea was higher in the untreated group, with median scores (higher is worse) of 2 for treated animals ( $n=13)$ and score $=6$ for 7 untreated calves. These Olivett et al. data were unsuitable for pooling (due to lack of variance). Both of the Schynder et al. cohorts (early and late treatment) observed more diarrhea in the intervention groups (see comparison below). The authors suspected that Niazoxanide was causing diarrhea in otherwise healthy animals. 
Figure 6. Diarrhoea intensity after treatment with Niazoxanide

\begin{tabular}{|c|c|c|c|c|c|c|c|c|c|}
\hline \multirow[b]{2}{*}{ Study or Subgroup } & \multicolumn{3}{|c|}{ Experimental } & \multicolumn{3}{|c|}{ Control } & \multirow{2}{*}{$\begin{array}{l}\text { Std. Mean Difference } \\
\text { IV, Random, } 95 \% \mathrm{Cl}\end{array}$} & \multirow{2}{*}{$\begin{array}{c}\text { Std. Mean Difference } \\
\text { IV, Random, } 95 \% \mathrm{Cl}\end{array}$} & Risk of Bias \\
\hline & Mean & SD & Total & Mean & SD & Total & & & A B C D E F G \\
\hline \multicolumn{10}{|c|}{ 11.2.1 RCT start treatment $<5 \mathrm{~d}$ old } \\
\hline Schynder2009 & 5 & 1.7 & 3 & 1.7 & 1.2 & 3 & $1.79[-0.56,4.15]$ & 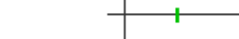 & 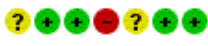 \\
\hline \multicolumn{10}{|c|}{ 11.2.3 RCT start treatment $5+d$ old } \\
\hline \multirow[t]{2}{*}{ Schynder2009 } & 6 & 1.7 & 3 & 1.7 & 1.2 & 3 & $2.34[-0.43,5.11]$ & & $? \odot \odot \odot ? \odot \odot$ \\
\hline & & & & & & & & $\begin{array}{cccc} & 1 & 1 & 1 \\
-4 & -2 & 0 & 2 \\
\text { aperimental] } & \text { Favours [c }\end{array}$ & \\
\hline
\end{tabular}

Risk of bias legend

(A) Assignment to treatments/controls randomised

(B) Confirmed CParvum status at start

(C) All animals accounted for at trial end

(D) Blinded both investigators \& carers

(E) Groups similar at the start of the trial

(F) Groups treated equally

(G) Results reported clearly for all stated trial outcomes

Schynder et al. did not provide data on oocyst shedding. Olivett et al. reported higher oocyst shedding in the control arm (median shedding observed over period was $3.87 \times 10^{7}$ for controls vs. $3.51 \times 10^{7}$ for intervention arm). The interquartile ranges on these medians were large and overlapping.

Schynder et al. did not comment on mortality. Olivett et al. reported incompletely about mortality, there was apparently at least one death but not clear from which arm.

A late CCT (Moon et al. 1982) tested a drug closely related to Niazoxanide, Metronidazole. Moon et al. observed equal oocyst shedding intensity in both treated and untreated animals (intensity score $=7$ ); no variance was supplied with this very small trial ( 2 calves in each arm). A very late RCT (animals age 2-3 yrs old deliberately infected in Masood et al. 2013) tested Metronidazole at doses of $100 \mathrm{mg} / \mathrm{kg}$ and 50 $\mathrm{mg} / \mathrm{kg}$ and looked for oocyst shedding. Similar to all of the antibiotics tested in Masood et al, Metronidazole was very effective at reducing the counts of oocysts shed (SMD about -4.0, $p<0.001$, either dose). Masood et al. reported some side effects (sweating, diarrhoea) and that weight gain was not significantly different between groups (cattle can keep growing until 7 years old). Diarrhoea was not recorded as an outcome between test groups and mortality was not mentioned in Masood et al.

Encouraging evidence did not emerge for Niazoxanide. Some encouraging evidence for a closely related drug, Metronidazole, was found (in Masood et al.) but this is very limited and not yet replicated. The evidence on these two drugs can generally be considered insufficient to recommend for or against it.

\section{Oligosaccharides}

Three trials tested oligosaccharides. Beta-cyclodextrin was tested in Pauling and Harapin (2008, a late RCT) with the main outcome being appetite recovery; they concluded that . "Calves treated with $\beta$ cyclodextrin electrolyte recovered their appetite more quickly". Diarrhoea, weight changes, oocyst shedding and mortality were not reported in Pauling \& Harapin.

Castro-Hermida et al. (2001) reported both an early CCT and a late CCT, testing Beta-cyclodextrin. They reported on mortality (none), diarrhea severity, oocyst shedding \& weight gain info. In the prophylactic arm there was significantly less severe diarrhoea (SMD $-2.47,95 \% \mathrm{Cl}-4.66$ to -0.28 ) and less oocyst 
shedding (albeit not significantly, SMD $-0.94,95 \% \mathrm{Cl}-2.47$ to 0.59 ). The authors also noticed a shorter duration of shedding in the early treatment arm.

Mannan oligosaccharide was tested in Terré et al. (2007, late RCT). Mortality was not commented upon. Terre et al. reported that there were "no differences in the incidence of loose feces between MR-C and MR-M treatments" but gave no supporting evidence. Terré et al. did provide information about average daily weight gain and oocyst shedding intensity. They concluded that although treated calves had higher weight gain until day 35 , by day 42 untreated animals had caught up (on day 42 , weight SMD was $0.10,95 \% \mathrm{Cl}-0.40$ to 0.61 ). Treated animals in Terré et al. shed significantly fewer oocysts (SMD $1.07,95 \% \mathrm{Cl}-1.61$ to -0.52$)$.

The figures below show comparisons for oocyst shedding intensity and weight gain information. Oligosaccharide treatment data are limited and encouraging that oligosaccharides may reduce oocyst shedding, but there is very little evidence (only 8 animals in the arm with best results) that this reduction leads to clinical benefits. Information is limited and mixed about impacts on diarrhea, and limited but suggest that there is no difference in weight gain after treatment.

Figure 7a. Weight gain after treatment with Oligosaccharides

\begin{tabular}{|c|c|c|c|c|c|c|c|c|c|}
\hline \multirow[b]{2}{*}{ Study or Subgroup } & \multicolumn{3}{|c|}{ Experimental } & \multicolumn{2}{|r|}{ Control } & \multicolumn{2}{|r|}{ Std. Mean Difference } & \multirow{2}{*}{$\begin{array}{l}\text { Std. Mean Difference } \\
\text { IV, Random, } 95 \% \mathrm{Cl}\end{array}$} & Risk of Bias \\
\hline & Mean & SD & Total & Mean & SD & Total & IV, Random, 95\% Cl & & A B C D E F G \\
\hline \multicolumn{10}{|c|}{ 12.1.1 early CCT, Beta-cyclodextrin } \\
\hline Castro-Hermida 2001 & 45 & 7.7 & 4 & 43.1 & 4.8 & 4 & $0.26[-1.14,1.65]$ & $1+$ & 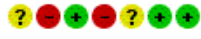 \\
\hline \multicolumn{10}{|c|}{ 12.1.2 late CCT, Beta-cyclodextrin } \\
\hline Castro-Hermida 2001 & 50.2 & 3.3 & 4 & 43.1 & 4.8 & 4 & $1.50[-0.23,3.23]$ & 1 & 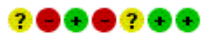 \\
\hline \multicolumn{10}{|c|}{ 12.1.3 late RCT, Mannan oligosaccharide } \\
\hline \multirow[t]{2}{*}{ Terré2007 (1) } & 85.3 & 7.7777 & 30 & 84.5 & 7.7777 & 30 & $0.10[-0.40,0.61]$ & + & ?९???૯? \\
\hline & & & & & & & & $\begin{array}{ccccc} & 1 & & 1 & 1 \\
-4 & -2 & 0 & 2 & 4 \\
\text { Favours [control] } & \text { Favours [ex }\end{array}$ & \\
\hline \multicolumn{8}{|c|}{ 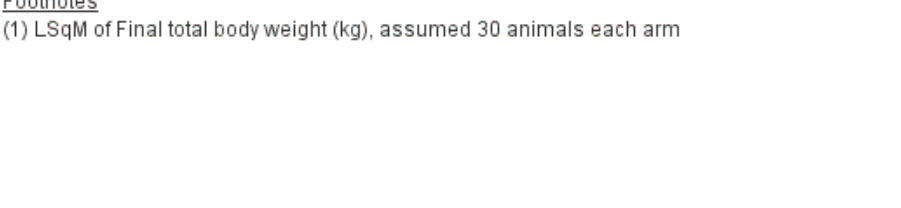 } & \multicolumn{2}{|c|}{$\begin{array}{l}\text { Risk of bias legend } \\
\text { (A) Assignment to treatments/controls randomised } \\
\text { (B) Confirmed CParvum status at start } \\
\text { (C) All animals accounted for at trial end } \\
\text { (D) Blinded both investigators \& carers } \\
\text { (E) Groups similar at the start of the trial } \\
\text { (F) Groups treated equally } \\
\text { (G) Results reported clearly for all stated trial outcomes }\end{array}$} \\
\hline
\end{tabular}


Figure 7b. Oocyst scores after treatment with Oligosaccharides

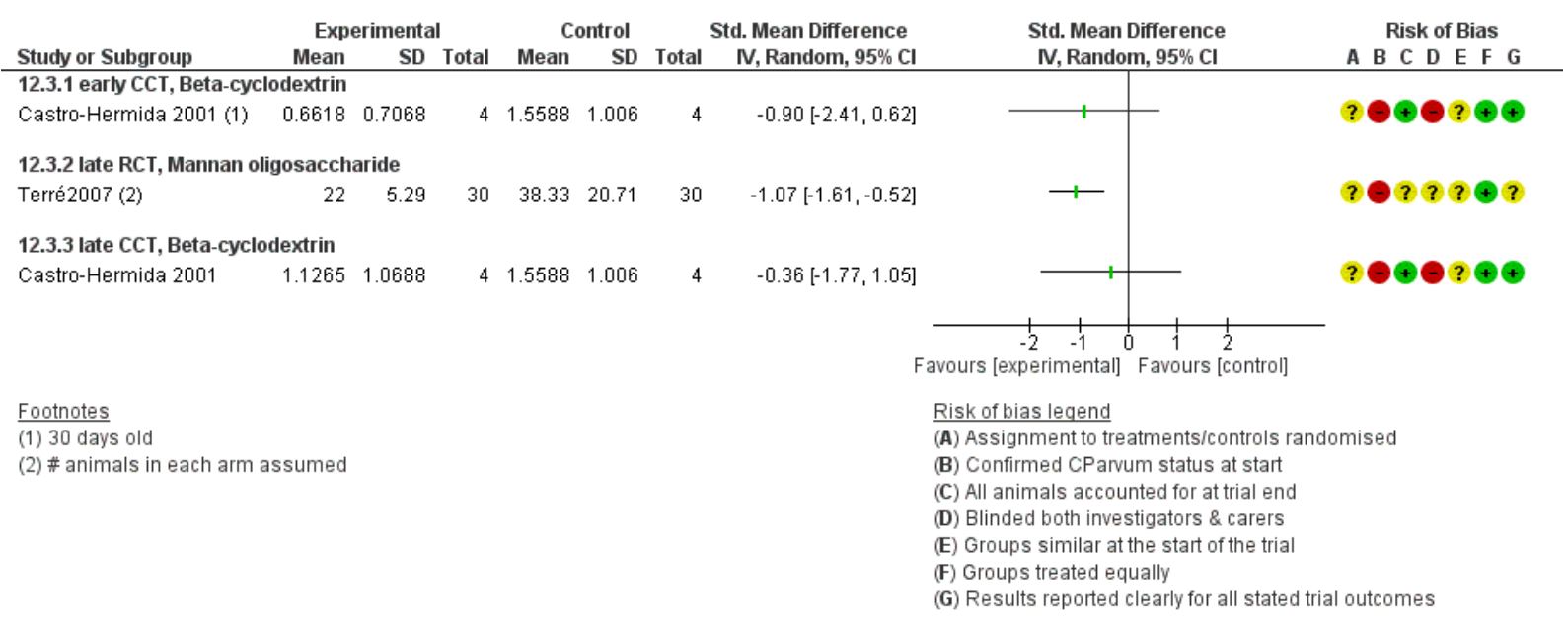

\section{Paromomycin}

Four trials tested this drug, one early CCT (Fayer and Ellis 1993), two early RCTs (Barberio et al. 2012; Grinberg et al. 2002) and one late RCT (Masood et al. 2013).

Weight gain: There were no data from Barberio et al. or Grinberg et al. Masood et al. stated that weight gain was not significantly different between groups but did not provide supporting data. Fayer \& Ellis 1993 reported the highest weight gain for both untreated animals (over first 28 days of life, $13.5 \mathrm{~kg}$, sd 1.32) and animals given a dose of $50 \mathrm{mg} / \mathrm{kg} /$ day $(14 \mathrm{~kg}$, sd 1.47). The animals given dosages of 100 $\mathrm{mg} / \mathrm{kg}$ or $25 \mathrm{mg} / \mathrm{kg}$ in contrast both had much lower weight gains (about $10.5 \mathrm{~kg}$ over the same period). Fayer \& Ellis is a very small trial ( $n=4$ animals in each arm) which makes this evidence insufficient as well as inconsistent.

Information about diarrhoea prevalence was provided by just two early RCTs (Barberio et al. 2012; Grinberg et al. 2002) and one late CCT (Fayer and Ellis 1993). Barberio et al. provided only the statistic that of animals with diarrhea, $10 \%$ of those treated with paromomycin were positive for C. parvum, while $38 \%$ of diarrheic animals not treated with paromycin were positive for C. parvum. Grinberg et al. reports that the diarrheal burden was lower in the experimental group, but not significantly so (SMD $0.62,-1.53$ to 0.28 ). All of the treated animals in Fayer \& Ellis (different doses, $n=4$ in each arm) had much lower diarrhea scores than the untreated calves (SMD around -4.6). Specific evidence about the impact of paromomycin on diarrhea incidence is limited (just 2 trials reported clearly) but promising (benefits reported in both experiments). 
Figure 8a. Fecal scores after treatment with paromomycin

\begin{tabular}{|c|c|c|c|c|c|c|c|c|c|c|}
\hline \multirow[b]{2}{*}{ Study or Subgroup } & \multicolumn{2}{|c|}{ Experimental } & \multirow[b]{2}{*}{ Total } & \multicolumn{2}{|c|}{ Control } & \multicolumn{2}{|c|}{ Std. Mean Difference } & \multirow{2}{*}{\multicolumn{2}{|c|}{$\begin{array}{l}\text { Std. Mean Difference } \\
\text { IV, Random, } 95 \% \mathrm{Cl}\end{array}$}} & Risk of Bias \\
\hline & Mean & SD & & Mean & SD & Total & IV, Random, $95 \% \mathrm{Cl}$ & & & $A B C D E F G$ \\
\hline \multicolumn{11}{|l|}{ 14.2.1 early RCT } \\
\hline Grinberg2002 (1) & 1.328571 & 0.398808 & 10 & 1.657143 & 0.591205 & 10 & $-0.62[-1.53,0.28]$ & ] & t & $\odot \odot \odot \odot ? ?$ \\
\hline \multicolumn{11}{|l|}{ 14.2.5 late CCT } \\
\hline Fayer1993 (2) & 4.25 & 2.07 & 4 & 17.5 & 3.18 & 4 & $-4.29[-7.56,-1.03]$ & 一 & & \\
\hline Fayer1993 (3) & 4.75 & 1.25 & 4 & 17.5 & 3.18 & 4 & $-4.59[-8.04,-1.14]$ & - & & \\
\hline \multirow[t]{2}{*}{ Fayer1993 (4) } & 3.5 & 1.5 & 4 & 17.5 & 3.18 & 4 & $-4.90[-8.54,-1.25]$ & 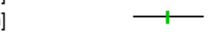 & & $? ? \odot$ \\
\hline & & & & & & & & $\begin{array}{cc}-20 & -10 \\
\text { Favours [experimental] }\end{array}$ & $\begin{array}{lc}0 & 10 \\
& 10 \\
\text { Favours [control] }\end{array}$ & 20 \\
\hline \multicolumn{8}{|c|}{$\begin{array}{l}\text { Footnotes } \\
\text { (1) Data reported were from LSQ transformation (not raw data) } \\
\text { (2) } 25 \mathrm{mg} \text { dose, avg rank score for entire period, paromomycin sulphate } \\
\text { (3) } 50 \mathrm{mg} \text { dose, avg rank score for entire period, paromomycin sulphate } \\
\text { (4) } 100 \mathrm{mg} \text { dose, avg rank score for entire period, paromomycin sulphate }\end{array}$} & \multicolumn{3}{|c|}{$\begin{array}{l}\text { Risk of bias legend } \\
\text { (A) Assignment to treatments/controls randomised } \\
\text { (B) Confirmed CParvum status at start } \\
\text { (C) All animals accounted for at trial end } \\
\text { (D) Blinded both investigators \& carers } \\
\text { (E) Groups similar at the start of the trial } \\
\text { (F) Groups treated equally } \\
\text { (G) Results reported clearly for all stated trial outcomes }\end{array}$} \\
\hline
\end{tabular}

Grinberg et al., Masood et al. and Fayer \& Ellis gave data on relative intensity of oocyst shedding. All studies were small ( $n=4$ in each arm) to moderate size (10-15 in each arm). All agreed that paromomycin reduced oocyst shedding (SMD around -3 ). Because of the small number of animals involved, inconsistent treatment protocols (early or late, RCT or CCT), unclear risk of bias in Massod et al., and how dated Fayer \& Ellis is, it is better to describe the evidence as promising rather than adequate or say that the drug provides demonstrable benefits.

Figure 18b. Oocyst shedding after paromomycin treatment vs. controls

\begin{tabular}{|c|c|c|c|c|c|c|c|c|c|}
\hline \multirow[b]{2}{*}{ Study or Subgroup } & \multicolumn{3}{|c|}{ Experimental } & \multicolumn{2}{|c|}{ Control } & \multicolumn{2}{|r|}{ Std. Mean Difference } & \multirow{2}{*}{$\begin{array}{c}\text { Std. Mean Difference } \\
\text { IV, Random, } 95 \% \mathrm{Cl}\end{array}$} & Risk of Bias \\
\hline & Mean & SD & Total & Mean & SD & Total & IV, Random, $95 \% \mathrm{Cl}$ & & A B C D E F G \\
\hline \multicolumn{10}{|c|}{ 14.3.1 RCT started treatment $<5 \mathrm{~d}$ old } \\
\hline Grinberg 2002 & 30 & 19 & 10 & 83 & 27 & 10 & $-2.17[-3.33,-1.02]$ & $千$ & $\odot \oplus \odot \ominus ? ? \odot$ \\
\hline \multicolumn{10}{|c|}{ 14.3.2 RCT started treatment age $2 \mathrm{yrs}^{+}$} \\
\hline Masood2013(1) & 435 & 194.7 & 15 & 1,237 & 166 & 15 & $-4.31[-5.69,-2.94]$ & 一 & ?????९ษ \\
\hline Masood2013 (2) & 399 & 227.7 & 15 & 1,237 & 166 & 15 & $-4.09[-5.41,-2.77]$ & 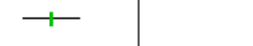 & ?????巳世 \\
\hline \multicolumn{10}{|l|}{ 14.3.3 CCT late } \\
\hline Fayer1993 (3) & 4.28 & 2.08 & 4 & 26.23 & 12.92 & 4 & $-2.06[-4.05,-0.08]$ & 1 & ?? \\
\hline Fayer1993 (4) & 5.18 & 4.85 & 4 & 26.23 & 12.92 & 4 & $-1.88[-3.77,0.02]$ & $\longrightarrow$ & \\
\hline Fayer1993 (5) & 0.1 & 0.1 & 4 & 26.23 & 12.92 & 4 & $-2.49[-4.69,-0.29]$ & 1 & (2) \\
\hline
\end{tabular}

\footnotetext{
Footnotes

(1) Paromomycin $50 \mathrm{mg} / \mathrm{kg}$

(2) Paromomycin $25 \mathrm{mg} / \mathrm{kg}$

(3) $50 \mathrm{mg} / \mathrm{kg}$ dose

(4) $25 \mathrm{mg} / \mathrm{kg}$ dose

(5) $100 \mathrm{mg} / \mathrm{kg}$ dose
}

\author{
Risk of bias legend \\ (A) Assignment to treatments/controls randomised \\ (B) Confirmed CParvum status at start \\ (C) All animals accounted for at trial end \\ (D) Blinded both investigators \& carers \\ (E) Groups similar at the start of the trial \\ (F) Groups treated equally \\ (G) Results reported clearly for all stated trial outcomes
}

Masood et al., Barberio and Fayer did not mention mortality so it is presumed there was none in those trials. Grinberg explicitly stated that there were no deaths in any arm. 
As is typical of the studies included in this review about any treatment, feed, supplement or management strategy, few comments were made about adverse effects of paromomycin. Masood et al observed some side effects (sweating, diarrhoea) in a small minority of animals.

The evidence base is promising but insufficient about paromomycin treatment. Two of the studies had at least four risk of bias domains that were low; this strengthens the certainty of these findings.

\section{Oral Oocyst vaccine administered to calves}

Two trials (a pilot study CCT, early treatment, Harp and Goff 1998) and an RCT (early treatment, Harp et al. 1996) tried lyophilizing purified C. parvum oocysts suspended in saline and administering this to calves on day of birth as an oral vaccine. Neither trial reported on weight gain differences.

Fecal scores were better in the treatment arm in the pilot study (SMD -0.78, -1.72 to 0.16 ), but not in the RCT (SMD -0.01, -0.42, 0.41).

Figure 9a. Fecal Scores after trials with an oral oocyst vaccine

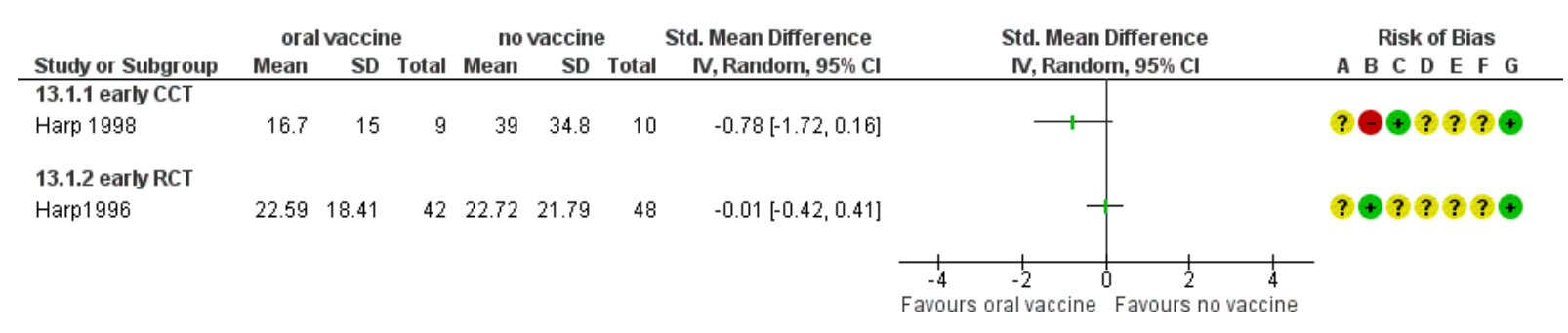

\footnotetext{
Risk of bias legend

(A) Assignment to treatments/controls randomised

(B) Confirmed CParvum status at start

(C) All animals accounted for at trial end

(D) Blinded both investigators \& carers

(E) Groups similar at the start of the trial

(F) Groups treated equally

(G) Results reported clearly for all stated trial outcomes
}

Intensity of oocyst shedding was also much lower in the pilot study for treated animals (SMD -0.98, 0.184 to 0.07 ) than in the RCT (SMD $0.17,-0.25$ to 0.58 ). The oral vaccine could not be shown to be effective in the larger trial for reducing oocyst shedding or diarrhea. 
Figure 9b. Oocyst Scores after trials with an oral oocyst vaccine

\begin{tabular}{|c|c|c|c|c|c|c|c|c|c|}
\hline \multirow{3}{*}{$\begin{array}{l}\text { Study or Subgroup } \\
\text { 13.2.1 early CCT }\end{array}$} & \multicolumn{3}{|c|}{ oral vaccine } & \multicolumn{3}{|c|}{ untreated } & \multirow{2}{*}{$\begin{array}{l}\text { Std. Mean Difference } \\
\text { IV, Random, } 95 \% \mathrm{Cl}\end{array}$} & \multirow{2}{*}{$\begin{array}{c}\text { Std. Mean Difference } \\
\text { IV, Random, } 95 \% \mathrm{Cl}\end{array}$} & Risk of Bias \\
\hline & Mean & SD & Total & Mean & SD & Total & & & A B C DEFG \\
\hline & & & & & & & & & \\
\hline Harp 1998 & 0.167 & 0.161 & 9 & 0.408 & 0.323 & 10 & $-0.89[-1.84,0.07]$ & 1 & ? $\odot \oplus ? ? ?$ \\
\hline 13.2.2 early RCT & & & & & & & & & \\
\hline Harp1996 & 37 & 24 & 42 & 33 & 24 & 48 & $0.17[-0.25,0.58]$ & + & ?૯? ? ? ? \\
\hline
\end{tabular}

Risk of bias legend

(A) Assignment to treatments/controls randomised

(B) Confirmed CParvum status at start

(C) All animals accounted for at trial end

(D) Blinded both investigators \& carers

(E) Groups similar at the start of the trial

(F) Groups treated equally

(G) Results reported clearly for all stated trial outcomes

Harp and Goff (1998) did not comment on mortality. Harp et al. (1996) said explicitly that there no deaths in any arm.

Evidence about oocysts vaccines based on inactivated lyophilized oocysts does not suggest consistent efficacy and is limited to one research team working $>25$ years ago. The evidence is not promising.

\section{Sulphadimine}

This drug was tested in 3 trials, including an early RCT with 50 animals in each arm (Joachim2003) and a very small late CCT (Moon 1982; $n=2$ each arm). Fischer et al 1983 is a CCT that describes four moderate-size treatment arms ( $n=29$ in each) with variable start dates and doses applied (mostly late).

No weight gain information was reported in Joachim or Moon. Fischer gave average daily gains at trial end (either 20 or 26 days) without variance; range was 0.6 to $0.8 \mathrm{~kg} /$ day. Fischer stated that this was negligible difference between arms.

Fecal consistency was not addressed by Moon. Information in Fischer was incomplete about diarrhea (available for controls but not intervention groups). Fischer concluded from their own analysis that the drug had had no impact on diarrhea prevalence. The between arm difference for the experiment in Joachim et al 2003 was SMD $-0.17,-0.56$ to 0.22 (experimental treatment not significantly protective).

Oocyst shedding was reported to have similar severity in the comparison arms in Moon (score $=7$ both). Again data are reported in different ways for control vs. experimental arms in Fischer, who concluded that there was no advantage for the treated animals. Joachim et al 2003 reported slightly less but insignificantly lower oocyst shedding in experimental arms (SMD $-0.09,-0.48$ to 0.30 ).

Mortality was reported to be insignificantly less in the control arm in the largest Sulphafimine trial, Joachim 2003 (enrolled 50 animals in each of 2 arms) reported an RR of 1.20 (0.39 to 3.68) favouring control but not significantly, modest size effect. Moon reported some deaths in their tests of many drugs, but it was unclear from which arms. Fischer did not mention deaths so it is presumed there were none in their trial. The evidence about Sulfadimine treatment is limited and not promising. 
Tylosin

Duru 2013 (late CCT) and Shobhamani 2007 (late RCT) both tested the antibiotic tylosin. Their only reported outcome was severity of oocyst shedding. There was no useable information on weight change, mortality or diarrhoeal intensity provided in either article. Only 43 animals were in all experimental arms.

The Figure below shows the SMD for oocyst shedding intensity in the respective trials. Information on Tylosiun is limited although encouraging for oocyst shedding, but it is unclear if this reduced shedding led to less morbidity.

Figure 10. Oocyst shedding intensity after treatment with tylosin

\begin{tabular}{|c|c|c|c|c|c|c|c|c|c|}
\hline \multirow{3}{*}{$\frac{\text { Study or Subgroup }}{\text { 16.3.1 late CCT }}$} & \multicolumn{3}{|c|}{ Experimental } & \multicolumn{2}{|c|}{ Control } & \multicolumn{2}{|r|}{ Std. Mean Difference } & \multirow{2}{*}{$\begin{array}{l}\text { Std. Mean Difference } \\
\text { IV, Random, } 95 \% \mathrm{Cl}\end{array}$} & Risk of Bias \\
\hline & Mean & SD & Total & Mean & SD & Total & IV, Random, $95 \% \mathrm{Cl}$ & & A B C D E F G \\
\hline & & & & & & & & & \\
\hline Duru2013 & 10.25 & 14.33 & 18 & 81.31 & 65.09 & 5 & $-2.20[-3.41,-0.98]$ & & ?૯૯? ? ?૯ \\
\hline 16.3.2 late RCT & & & & & & & & & \\
\hline Shobhamani2007 & 304.91 & 233.61 & 10 & 485.35 & 217.43 & 10 & $-0.77[-1.68,0.15]$ & 1 & ?? ? ? ? ? \\
\hline
\end{tabular}

Risk of bias legend

(A) Assignment to treatments/controls randomised

(B) Confirmed CParvum status at start

(C) All animals accounted for at trial end

(D) Blinded both investigators \& carers

(E) Groups similar at the start of the trial

(F) Groups treated equally

(G) Results reported clearly for all stated trial outcomes 
Table 1. Other treatments tried

\begin{tabular}{|c|c|c|}
\hline $\begin{array}{c}\text { Study } \\
\text { Design, timing } \\
\text { \#Intvn(s)...:\#controls }\end{array}$ & $\begin{array}{c}\text { Test } \\
\text { comparison(s) }\end{array}$ & Authors' own conclusions about treatment \\
\hline $\begin{array}{c}\text { Alidadi et al. (2008) } \\
\text { RCT:late } \\
\text { Unclear }\end{array}$ & $\begin{array}{c}\text { Intramuscular } \\
\text { injections of } \\
\text { buparvaquone, } 2.5 \\
\mathrm{mg} / \mathrm{kg}\end{array}$ & Not significantly effective \\
\hline $\begin{array}{c}\text { Aoki et al. (2011) } \\
\text { CCT:early } \\
\text { 3:3:3 }\end{array}$ & $\begin{array}{l}\text { Colostrum from dams } \\
\text { who had E. Coli } \\
\text { vaccine (different } \\
\text { doses) }\end{array}$ & $\begin{array}{l}\text { No protective effect against } \mathrm{C} \text {. parvum infection was } \\
\text { obtained }\end{array}$ \\
\hline $\begin{array}{c}\text { Askari et al. (2016) } \\
\text { CCT:early } \\
5: 5\end{array}$ & $\begin{array}{l}\text { Colostrum from dams } \\
\text { repeatedly (from } 70 \\
\text { days prior to } \\
\text { parturition) } \\
\text { immunised with } \\
\text { vaccine containing } \\
\text { P23 = } 23 \text { kDa surface } \\
\text { glycoprotein }\end{array}$ & $\begin{array}{l}\text { Calves fed (from vaccinated dams) hyperimmune colostrum did } \\
\text { not show cryptosporidiosis signs (after deliberate challenge at } 12 \\
\text { h old) up to } 2 \text { weeks old, and had very significantly lower oocyst } \\
\text { excretion }\end{array}$ \\
\hline $\begin{array}{c}\text { Björkman et al. } \\
\text { (2018) CCT:early } \\
\text { 196:206 }\end{array}$ & $\begin{array}{l}\text { Lime disinfection of } \\
\text { individual pens } \\
\text { before calves were } \\
\text { put in them }\end{array}$ & $\begin{array}{l}\text { No difference between lime disinfected and control pens WRT } \\
\text { oocyst shedding or diarrhoea incidence. Disinfection of calf } \\
\text { pens with slaked lime delayed onset of diarrhea and improved } \\
\text { the body condition in the calves, but not diarrhea duration. }\end{array}$ \\
\hline $\begin{array}{c}\text { Carvalho et al. (2014) } \\
\text { CCT:early } \\
9: 8\end{array}$ & $\begin{array}{l}2 \text { litres more of milk } \\
\text { replacer/day }\end{array}$ & $\begin{array}{l}\text { C. parvum was found more often in lower feed group (not signif. } \\
\text { Difference). Different volumes of milk replacer did not } \\
\text { influence the incidence and etiology of neonatal diahrrea. }\end{array}$ \\
\hline $\begin{array}{l}\text { Connor et al. (2017) } \\
\text { CCT:early } \\
\text { 6:6:6 } \\
\text { (+6 uninfected) }\end{array}$ & $\begin{array}{l}\text { Glucagon-like peptide } \\
2 \text { (GLP-2), food } \\
\text { supplement = Sucram }\end{array}$ & $\begin{array}{l}\text { Calves receiving control buffer injection had higher diarrhoea } \\
\text { severity than untreated controls; calves in SUC or GLP arms had } \\
\text { less shedding and other clinical outcome improvements } \\
\text { compared to infected+untreated animals }\end{array}$ \\
\hline $\begin{array}{l}\text { Derbakova et al. } \\
\text { (2016) CCT:early } \\
\text { 10:10 }\end{array}$ & $\begin{array}{l}\text { Sea buckthorn, berry } \\
\text { pomace extract }\end{array}$ & $\begin{array}{l}\text { No significant }(p>0.05) \text { difference in the number of oocysts per } \\
\text { gram of feces between the experimental and control groups }\end{array}$ \\
\hline $\begin{array}{l}\text { Glover et al. (2013) } \\
\text { RCT: early } \\
\text { 28:25:26 }\end{array}$ & $\begin{array}{l}3 \text { arm trial, } 2 \\
\text { doses of zinc } \\
\text { oxide }\end{array}$ & $\begin{array}{l}\text { Higher (not significantly) weight gain and quicker to obtain } \\
\text { negative status }\end{array}$ \\
\hline $\begin{array}{l}\text { Graef et al. (2018) } \\
\text { CCT:early } \\
14: 9\end{array}$ & $\begin{array}{l}\text { Confinement } \\
\text { housing }{ }^{1} \text { vs. box } \\
\text { stalls }\end{array}$ & $\begin{array}{l}\text { Confinement housed calves shed significantly more oocysts }(P= \\
0.05) \text {, had higher plasma cortisol }(P=0.001) \text {, and required more } \\
\text { supportive care }(P=0.0009) \text { than calves in box stalls. }\end{array}$ \\
\hline $\begin{array}{l}\text { Higginbotham et al. } \\
\text { (1998) RCT: early } \\
\text { 19:19 }\end{array}$ & $\begin{array}{l}\text { Pro-biotic, multi- } \\
\text { ingredient }\end{array}$ & $\begin{array}{l}\text { No appreciable effects on C. parvum oocyst shedding; no effect } \\
\text { on body weight indicators or feed efficiency. }\end{array}$ \\
\hline $\begin{array}{c}\text { Hunt et al. (2002) } \\
\text { CCT:late } \\
12: 8\end{array}$ & $\begin{array}{l}\text { Bovine serum } \\
\text { concentrate }\end{array}$ & $\begin{array}{l}\text { Peak diarrhoeal volume and intestinal permeability were } \\
\text { reduced by } 33 \% \text {, also fewer oocysts were shed }\end{array}$ \\
\hline
\end{tabular}

\footnotetext{
${ }^{1}$ Also known as 'crating' (crating is illegal in EU). Confinement housing allows calves to lie down but not to turn around or groom, often have slatted flooring. In contrast, box stalls allow natural movement and are much larger pens; these box stalls also had soft bedding (straw).
} 
Imboden et al. (2012) antibody-biocide RCT:early

8:8

Keidel and Daugschies (2013)

RCT:early

24:24 \& 24:24

Meganck et al. (2015)

RCT:early

296:234

\section{Nasir et al. (2013) \\ RCT:late \\ 5:5:5}

Ollivett et al. (2012)

RCT:early

11:9

Olson et al. (1998)

RCT:early

17:18

Pasquali et al. (2006)

CCT:early

4:4:4

Perryman et al. (1999)

RCT:early

6:6

Quigley et al. (1995)

RCT:early

24:24:24:24

Raabis et al. (2015,

2018) RCT:early

71:62

Stebbins et al. (2018)

CCT:late

6:7

Todd et al. (2017)

CCT:early

249:249

Vélez et al. (2019)

CCT:early

41:41

Watarai et al. (2008)

RCT:late

3:3

chloro-m-cresol =

Neopredisan

E.Coli vaccine to

dams and HFG to calves

Kalvangi seed powder, cotrimoxazole replacer

$$
\text { Allicin }
$$

(garlic extract)

Recombinant bovine

interleukin-12

Colostrum from

dams who had $C$.

parvum vaccine

Botted or nursed colostrum

Egg yolk powder with anti-IL-10 antibodies

Piperazine-based compound MMV665917

Accidified milk replacer

SCFP (Diamond V SmartCare ${ }^{\circledR}$ at 1 $\mathrm{g} / \mathrm{d}$ in milk and NutriTek ${ }^{\circledR}$ at 5 $\mathrm{g} / \mathrm{d}$ in starter grain) for the first 63 days of life

Charcoal vinegar
Reduced severity of disease (diarrhea) and reduced oocyst shedding

Neopredisan disinfection did not lead to significantly lower oocyst shedding or diarrhea.

High protein milk
No significant differences between control and treatment group were observed in the percentage of calves excreting E. coli, rotavirus and coronavirus, both before and at the end of the trial.

Both Ineffective against C. parvum infection

After challenge, calves on higher nutrition plane had shorter duration diarrhea, grew faster and converted feed with greater efficiency

No difference in duration of diarrhea, or weight gain, but delay in onset of diarrhea was seen

\section{Treatment did not alter the course of infection}

All calves who received colostrum from unvaccinated dams developed diarrhea; no calves who received colostrum from vaccinated dams got diarrhea. Fewer oocysts were shed from calves who had vacc-dam colostrum

Prevalence of $\mathrm{C}$. parvum in fecal samples was not reduced or greater depending how they received colostrum

Lower prevalence shedding of C. parvum oocysts

Effective at reducing shedding and diarrhea. Both control and intervention animals received intensive supportive care, too. Monitoring stopped after 7 days

Higher weight gain and fewer comorbidities but only during treatment period

Mortality, oocyst intensity \& diarrhoea: little different from controls or HFG-treated group. Wt gain: mean values did not differ significantly $(p=0.306)$ among the treatment groups

Significantly less fecal excretion of $C$. parvum oocysts was observed, oocyst-negative much earlier, too 


\section{Weyl-Feinstein et al. (2014) RCT:early 16:19:35}

Yagci et al. (2017) RCT:early $30: 25$

\author{
Summer and \\ winter \\ pomegranate \\ extracts \\ Toltrazuril \\ (antibiotic)
}

Reduced fecal oocyst count and diarrhea intensity and duration in the $3.75 \%$ extract Calves (but no difference in weight gain). At lower dose, there were lesser effects although weight gain was greater and diarrhoea duration shorter in treated animals

Treated animals shed fewer oocysts. Clinical health scores were better for treated animals than for controls.

\section{Discussion}

The evidence base is at least encouraging but insufficient about paromomycin, bumped kinase inhibitors or azithromycin treatment, especially for diarrhea and oocyst shedding, given late or early.

Azithromycin is the most promising of these. Azithromycin may be effective as treatment for cryptosporiodic calves $>4$ days old, too.

Putting young calves in individual hutches rather than shared pens seems likely to be protective. Decoquinate may be effective at reducing mortality. Many things (eg. Colostral whey) were reported as effective at reducing oocyst shedding but it is not clear if this reduction could be clinically important. Most things have been tested in too few trials to say anything very confidently about them.

Evidence is very limited and therefore very inconclusive ( $<2$ comparisons for any outcome, separated by early and late treatment) for many specific antimicrobial treatments. There is some encouraging evidence from these other single-trial specific treatment regimes, but they are not definitive. Most trials were too small and didn't consider costs of treatment and a wide range of relevant outcomes. It is also clear from many trials that just reducing oocyst shedding does not necessarily prevent affect negative outcomes: death, poor weight gain and/or diarrhea. We also note that some of the treatments described here may not be licensed for use within specific geographic regions. Azithromycin is not licensed for use on young animals in the European Union, for instance. Our results may be worth considering with regard to future licensing decisions.

In parallel research (Author-names-suppressed under review) we found strong evidence that halofuginone (HFG) treatment in young calves can reduce mortality and diarrhea, but there is merit in exploring what other strategies or pharmacological products may be effective to reduce harms from cryptosporidiosis, not least because the therapeutic dose of HFG is narrow. Toxicity can be achieved at a dose only double that of the safe dose (European Medicines Agency 2007). Stories of young animal deaths from excessive doses are not unheard of (Anonymous 2018).

\section{Limitations}

We did not try to report on adverse events following treatment. We observed that very few studies reported systematically on adverse effects of any treatment regime. Poor reporting about adverse effects from trial regimes or drugs is problematic in trying to evaluate evidence. The evidence base was also too small ( $\leq 4$ studies for any treatment tested) to conclusively look for publication bias using funnel plots. 
Subgrouping by whether trials had been sponsored by industry was not done but would be ideal with a larger number of eligible trials. The nutritional status of calves and their husbandry conditions or vaccination status (against other diarrheal diseases) would also be worthwhile to consider, but was not realistic to consider with so few trials for any specific treatment. Vaccination against other viruses known to cause diarrheal disease in cows might make animals more resistant to cryptosporidiosis; subgrouping by vaccination status could be informative with a larger evidence base.

\section{Conclusions}

There is not consistent evidence for use of any specific non-HFG intervention to reduce cryptosporidiosis in young calves. Some specific treatments or strategies are encouraging or promising for specific outcomes, however. To accompany any such future experiments, adverse effects, animal-welfare specific outcomes and costs of application should be reported to achieve fully informed best practice.

Supplementary File 1: Quality Assessment questions with decision criteria Supplementary Table 2: Quality Assessment (risk of bias, completeness of reporting) for each study included in the review

\section{Author contributions}

PRH and KT conceived the study. JB and CCH designed the study. JB conducted the searches, JB and $\mathrm{CCH}$ screened, read full text and extracted. JB undertook analysis, wrote first draft and assembled revisions. All authors revised draft manuscripts and approve the final manuscript.

\section{Conflicts of Interest}

All authors declare that we have no conflicts of interest.

\section{Acknowledgements}

This project received funding from the Interreg 2 Seas programme 2014-2020 co-funded by the European Regional Development Fund under subsidy contract No 2S05-043 H4DC. The opinions expressed here are those of the authors only. Thanks to Chris Groom and Kate West (staff at the Norwich BioScience Institutes) for help with literature searches.

\section{REFERENCES}

1. Alidadi N, et al. (2008) Effect of buparvaquone on Cryptosporidium parvum oocysts shedding in calf. Asian Journal of Animal and Veterinary Advances 3(4):275-277 doi:10.3923/ajava.2008.275.277

2. Anonymous (2018) Disease surveillance in England and Wales. Veterinary Record 183:11-15

3. Aoki M, Niwa Y, Komatsu T, Okada K, Yasuda J, Itagaki T (2011) Effects of feeding colostrum from E. coli vaccinated dams on protection against Cryptosporidium parvum and lymphocyte subset population in neonatal calves. Japanese Journal of Large Animal Clinics 2(1):7-13

4. Askari N, et al. (2016) Evaluation of recombinant P23 protein as a vaccine for passive immunization of newborn calves against Cryptosporidium parvum. Parasite Immunology 38(5):282-289 doi:http://dx.doi.org/10.1111/pim.12317 
5. Author-names-suppressed (under review) Efficacy of halofuginone products to prevent or treat cryptosporidiosis: A systematic review.

6. Barberio A, et al. (2012) Impiego dell'amminosidina solfato per la prevenzione

7. della criptosporidiosi nel vitello Rivista di Medicina Veterinaria 47(2):19-27

8. Beaver A, Meagher RK, von Keyserlingk MA, Weary DM (2019) A systematic review of the effects of early separation on dairy cow and calf health. Journal of Dairy Science 102(7):5784-5810

9. Björkman C, von Brömssen C, Troell K, Svensson C (2018) Disinfection with hydrated lime may help manage cryptosporidiosis in calves. Veterinary Parasitology 264:58-63 doi:10.1016/j.vetpar.2018.11.004

10. Brankston G, Boughen C, Ng V, Fisman DN, Sargeant JM, Greer AL (2018) Assessing the impact of environmental exposures and Cryptosporidium infection in cattle on human incidence of cryptosporidiosis in Southwestern Ontario, Canada. PloS One 13(4):e0196573

11. Cacci S, Chalmers RM (2016) Human cryptosporidiosis in Europe. Clinical Microbiology and Infection 22(6):471-480

12. Carvalho JG, et al. (2014) Longitudinal study of infection by enteropathogens in newborn calves with diarrhea under different feeding strategies. Pesquisa Veterinaria Brasileira 34(6):529-536 doi:10.1590/S0100-736X2014000600006

13. Castro-Hermida JA, González-Losada Y, Freire-Santos F, Mezo-Menéndez M, Ares-Mazás E (2001) Evaluation of $\beta$-cyclodextrin against natural infections of cryptosporidiosis in calves. Veterinary Parasitology 101(2):85-89 doi:10.1016/S0304-4017(01)00505-2

14. Connor EE, et al. (2017) Reducing gut effects from Cryptosporidium parvum infection in dairy calves through prophylactic glucagon-like peptide 2 therapy or feeding of an artificial sweetener. Journal of Dairy Science 100(4):3004-3018 doi:http://dx.doi.org/10.3168/ids.2016-11861

15. De Waele V, Speybroeck N, Berkvens D, Mulcahy G, Murphy TM (2010) Control of cryptosporidiosis in neonatal calves: use of halofuginone lactate in two different calf rearing systems. Preventive veterinary medicine 96(3-4):143-151

16. Deeks JJ, Higgins J, Altman DG, Green S (2011) Cochrane handbook for systematic reviews of interventions version 5.1. 0 (updated March 2011). The Cochrane Collaboration:2

17. Derbakova A, Keidane D, Liepa L, Zolnere E The effect of sea buckthorn (Hippophae Rhamnoides) extract on Cryptosporidium Spp. invasion in calves. 2016. vol 1. p 140-143

18. Elitok B, Elitok OM, Pulat $H$ (2005) Efficacy of azithromycin dihydrate in treatment of cryptosporidiosis in naturally infected dairy calves. Journal of Veterinary Internal Medicine 19(4):590-593 doi:http://dx.doi.org/10.1892/08916640\%282005\%2919\%5B590:EOADIT\%5D2.0.CO;2

19. Erbe $S$ (2010) Bovine cryptosporidiosis: analysis of an integrated control under the conditions of a natural infection position in a calf herd. University of Leipzig

20. European Medicines Agency (2007) HALOCUR: EPAR summary for the public European Public Assessment Report. p 2

21. Fayer R, Ellis W (1993) Paromomycin is effective as prophylaxis for cryptosporidiosis in dairy calves. Journal of Parasitology 79(5):771-774 doi:10.2307/3283619

22. Glover AD, et al. (2013) A double-blind block randomized clinical trial on the effect of zinc as a treatment for diarrhea in neonatal Holstein calves under natural challenge conditions.

Preventive Veterinary Medicine 112(3-4):338-347 doi:http://dx.doi.org/10.1016/i.prevetmed.2013.09.001

23. Graef G, et al. (2018) Impact of confinement housing on study end-points in the calf model of cryptosporidiosis. PLoS Neglected Tropical Diseases 12(4) doi:10.1371/journal.pntd.0006295 
24. Grinberg A, Lopez-Villalobos N, Markovics A, Kosak A, Galindez J, Tranquillo VM (2002) Controlling the onset of natural cryptosporidiosis in calves with paromomycin sulphate. Veterinary Record 151(20):606-608 doi:http://dx.doi.org/10.1136/vr.151.20.606

25. Grindlay DJ, Brennan ML, Dean RS (2012) Searching the veterinary literature: a comparison of the coverage of veterinary journals by nine bibliographic databases. Journal of Veterinary Medical Education 39(4):404-412

26. Harp JA, Goff JP (1998) Strategies for the Control of Cryptosporidium parvum Infection in Calves. Journal of Dairy Science 81(1):289-294 doi:10.3168/jds.S0022-0302(98)75578-X

27. Harp JA, et al. (1996) Field testing of prophylactic measures against Cryptosporidium parvum infection in calves in a California dairy herd. American Journal of Veterinary Research 57(11):1586-1588

28. Higginbotham GE, Robison JD, Atwill ER, Das Gracas M, Pereira C (1998) Effect of a Direct-Fed Microbial Product on Calf Performance and Fecal Flora. Professional Animal Scientist 14(2):108113 doi:10.15232/S1080-7446(15)31803-9

29. Higgins J, Wells G (2011) Cochrane handbook for systematic reviews of interventions.

30. Hunt E, et al. (2002) Oral bovine serum concentrate improves cryptosporidial enteritis in calves. Pediatric Research 51(3):370-376 doi:http://dx.doi.org/10.1203/00006450-200203000-00017

31. Hunter PR, Thompson RA (2005) The zoonotic transmission of Giardia and Cryptosporidium. International Journal for Parasitology 35(11-12):1181-1190

32. Imboden M, Schaefer DA, Bremel RD, Homan EJ, Riggs MW (2012) Antibody fusions reduce onset of experimental Cryptosporidium parvum infection in calves. Veterinary Parasitology 188(1-2):41-47 doi:http://dx.doi.org/10.1016/j.vetpar.2012.02.014

33. Imre K, Dărăbus G (2011) Distribution of Cryptosporidium species, genotypes and C. parvum subtypes in cattle in European countries. Revista Sci Parasitol 12(1):1-9

34. Johnson K, Burn CC, Wathes DC (2011) Rates and risk factors for contagious disease and mortality in young dairy heifers. Animal Science Reviews 205:101-113

35. Keidel J, Daugschies A (2013) Integration of halofuginone lactate treatment and disinfection with $\mathrm{p}$-chloro-m-cresol to control natural cryptosporidiosis in calves. Veterinary Parasitology 196(3-4):321-326 doi:http://dx.doi.org/10.1016/i.vetpar.2013.03.003

36. Lallemond M, Villeneuve A, Belda J, Dubreuil P (2006) Field study of the efficacy of halofuginone and decoquinate in the treatment of crytosporidiosis in veal calves. Veterinary Record 159(20):672-677

37. Lendner M, Bottcher D, Delling C, Ojo KK, Van Voorhis WC, Daugschies A (2015) A novel CDPK1 inhibitor-a potential treatment for cryptosporidiosis in calves? Parasitology Research 114(1):335-336 doi:http://dx.doi.org/10.1007/s00436-014-4228-7

38. Masood S, Maqbool A, Khan UJ, Chaudhry ZI, Anjum AA (2013) Anti-Cryptosporidium activity of albendazole, metronidazole and paromomycin in experimentally infected cattle. Pakistan Journal of Zoology 45(4):935-940

39. Meganck V, Hoflack G, Piepers S, Opsomer G (2015) Evaluation of a protocol to reduce the incidence of neonatal calf diarrhoea on dairy herds. Preventive Veterinary Medicine 118(1):6470

40. Moon H, Woode G, Ahrens F (1982) Attempted chemoprophylaxis of cryptosporidiosis in calves. The Veterinary Record 110(8):181

41. Moore DA, et al. (2003) Prophylactic use of decoquinate for infections with Cryptosporidium parvum in experimentally challenged neonatal calves. Journal of the American Veterinary Medical Association 223(6):839-845 doi:http://dx.doi.org/10.2460/javma.2003.223.839

42. Murakoshi F, et al. (2014) Administration of lasalocid-NA is preventive against cryptosporidiosis of newborn calves. Veterinary Record 175(14):353 doi:10.1136/vr.102508 
43. Nasir A, Avais M, Khan MS, Khan JA, Hameed S, Reichel MP (2013) Treating cryptosporidium parvum infection in Calves. Journal of Parasitology 99(4):715-717 doi:10.1645/12-42.1

44. Olias P, Dettwiler I, Hemphill A, Deplazes P, Steiner A, Meylan M (2018) The significance of cryptosporidiosis for the health of calves in Switzerland. Schweizer Archiv fur Tierheilkunde 160(6):363-374

45. Ollivett TL, et al. (2009) Effect of nitazoxanide on cryptosporidiosis in experimentally infected neonatal dairy calves. Journal of Dairy Science 92(4):1643-1648 doi:10.3168/jds.2008-1474

46. Ollivett TL, Nydam DV, Linden TC, Bowman DD, Van Amburgh ME (2012) Effect of nutritional plane on health and performance in dairy calves after experimental infection with Cryptosporidium parvum. Journal of the American Veterinary Medical Association 241(11):15141520 doi:10.2460/javma.241.11.1514

47. Olson EJ, Epperson WB, Zeman DH, Fayer R, Hildreth MB (1998) Effects of an allicin-based product on cryptosporidiosis in neonatal calves. Journal of the American Veterinary Medical Association 212(7):987-990

48. Pasquali $P$, et al. (2006) Recombinant bovine interleukin-12 stimulates a gut immune response but does not provide resistance to Cryptosporidium parvum infection in neonatal calves. Veterinary Parasitology 135(3-4):259-268 doi:10.1016/j.vetpar.2005.05.062

49. Pauling B, Harapin I A field report to compare the responses in calves with diarrhoea associated with cryptosporidiosis when treated with electrolytes with or without betacyclodextrin.

Proceedings of the XVI Congress of the Mediterranean Federation for Health and Production of Ruminants, Zadar, Croatia2008.

50. Perryman LE, Kapil SJ, Jones ML, Hunt EL (1999) Protection of calves against cryptosporidiosis with immune bovine colostrum induced by a Cryptosporidium parvum recombinant protein. Vaccine 17(17):2142-2149 doi:10.1016/S0264-410X(98)00477-0

51. Quigley JD, III, et al. (1995) Effects of Housing and Colostrum Feeding on Serum Immunoglobulins, Growth, and Fecal Scores of Jersey Calves. Journal of Dairy Science 78(4):893901 doi:10.3168/jds.S0022-0302(95)76703-0

52. Raabis S, McGuirk S, Rieman J, Sand J, Cook M (2015) Health benefits of IL-10 Egg yolk antibodies administered to milk-fed dairy calves. Journal of Veterinary Internal Medicine Conference:2015 ACVIM Forum Research. United States. 29 (4) (pp 1252)

53. Raabis SM, Ollivett TL, Cook ME, Sand JM, McGuirk SM (2018) Health benefits of orally administered anti-IL-10 antibody in milk-fed dairy calves. Journal of Dairy Science 101(8):73757382 doi:10.3168/jds.2017-14270

54. Robert B, Collard A, Coppe P, Ginter A, Antoine H (1991) Epidémiologie de la cryptosporidiose bovine dans une ferme belge; essai de prévention à l'aide de colostrum. Ann Méd Vét 135:441446

55. Schaefer DA, et al. (2016) Novel bumped kinase inhibitors are safe and effective therapeutics in the calf clinical model for cryptosporidiosis. Journal of Infectious Diseases 214(12):1856-1864 doi:10.1093/infdis/jiw488

56. Schnyder M, Kohler L, Hemphill A, Deplazes P (2009) Prophylactic and therapeutic efficacy of nitazoxanide against Cryptosporidium parvum in experimentally challenged neonatal calves. Veterinary Parasitology 160(1-2):149-154 doi:http://dx.doi.org/10.1016/i.vetpar.2008.10.094

57. Shaw H (2014) Digest Paper - Cryptosporidiosis in calves, the economic impact and best control measures. British Cattle Breeders Club

58. Shobhamani B, Alaha Singari N, Syaamasundar N (2007) Efficacy of azithromycin and tylosin against cryptosporidiosis. Journal of Veterinary Parasitology 21(1):47-49

59. Silverlås C, Björkman C, Egenvall A (2009) Systematic review and meta-analyses of the effects of halofuginone against calf cryptosporidiosis. Preventive Veterinary Medicine 91(2-4):73-84 
60. Slacek B, Ankenbauer-Perkins KL, Tunnicliffe A (1996) Evaluation of colostrum and whey-derived gammaglobulins for prevention of cryptosporidiosis in artificially infected neonatal calves. New Zealand Veterinary Journal 44(4):158-160 doi:10.1080/00480169.1996.35962

61. Stebbins E, et al. (2018) Clinical and microbiologic efficacy of the piperazine-based drug lead MMV665917 in the dairy calf cryptosporidiosis model. PLoS Neglected Tropical Diseases 12(1) doi:http://dx.doi.org/10.1371/journal.pntd.0006183

62. Taylor M, Bartram D (2012) The history of decoquinate in the control of coccidial infections in ruminants. Journal of Veterinary Pharmacology and Therapeutics 35(5):417-427

63. Terré M, Calvo MA, Adelantado C, Kocher A, Bach A (2007) Effects of mannan oligosaccharides on performance and microorganism fecal counts of calves following an enhanced-growth feeding program. Animal Feed Science and Technology 137(1-2):115-125 doi:10.1016/j.anifeedsci.2006.11.009

64. Thomson S, et al. (2017) Bovine cryptosporidiosis: impact, host-parasite interaction and control strategies. Veterinary Research 48(1):42

65. Todd CG, et al. (2017) Clinical trial on the effects of a free-access acidified milk replacer feeding program on the health and growth of dairy replacement heifers and veal calves. Journal of dairy science 100(1):713-725 doi:http://dx.doi.org/10.3168/jds.2016-11401

66. Toews LC (2017) Compliance of systematic reviews in veterinary journals with Preferred Reporting Items for Systematic Reviews and Meta-Analysis (PRISMA) literature search reporting guidelines. Journal of the Medical Library Association 105(3):233

67. Vélez J, Lange MK, Zieger P, Yoon I, Failing K, Bauer C (2019) Long-term use of yeast fermentation products in comparison to halofuginone for the control of cryptosporidiosis in neonatal calves. Veterinary Parasitology 269:57-64 doi:10.1016/j.vetpar.2019.04.008

68. Vermeulen LC, Benders J, Medema G, Hofstra N (2017) Global Cryptosporidium loads from livestock manure. Environmental Science \& Technology 51(15):8663-8671

69. Watarai S, Tana, Koiwa M (2008) Feeding activated charcoal from bark containing wood vinegar liquid (Nekka-Rich) is effective as treatment for cryptosporidiosis in calves. Journal of Dairy Science 91(4):1458-1463 doi:10.3168/jds.2007-0406

70. Wells B, Thomson S (2014) Cryptosporidiosis in Cattle News sheet. vol 6, Edinburgh UK, p 12

71. Weyl-Feinstein S, et al. (2014) Short communication: Effect of pomegranate-residue supplement on Cryptosporidium parvum oocyst shedding in neonatal calves. Journal of Dairy Science 97(9):5800-5805 doi:10.3168/jds.2013-7136

72. Yagci BB, Ocal N, Yasa Duru S, Akyol M (2017) The efficacy of a combination of azithromycin and toltrazuril for the treatment of calves naturally infected with cryptosporidiosis: A randomised, double-blind, placebo-controlled comparative clinical trial. Veterinarni Medicina 62(6):308-314 doi:http://dx.doi.org/10.17221/125/2015-VETMED 